\title{
Aboriginality, Inclusion and Public Space in the City of Edmonton
}

by

\author{
Amenah Gulamhusein
}

A thesis submitted to the Faculty of Graduate and Postdoctoral Affairs in partial fulfillment of the requirements for the degree of

Master of Arts

in

Public Administration

Carleton University

Ottawa, Ontario

(C) 2014, Amenah Gulamhusein 


\section{Abstract}

This thesis applies the theory of the right to the city (Lefebvre, 1991), and the concept of social inclusion (Burchardt, Le Grand, \& Piachaud, 2002) to argue that access to public space impacts the level of inclusion experienced by Aboriginal peoples in Edmonton.

This work begins with an overview of the historical discourses that depict Aboriginal peoples as out of place in urban society, and presents the contemporary realities of urban Aboriginal communities. This is followed by the identification of six elements that distinguish the urban Aboriginal community from reserve based communities and other visible minority urban residents. Lastly, information from focus groups with Aboriginal people and semi-structured interviews with organizational representatives are used to consider Aboriginal peoples engagement in the decision making processes related to the design, use and management of space; identify barriers to inclusion; and explore the mechanisms being used by Aboriginal people to appropriate space within their communities. 


\section{Acknowledgements}

I wish to extend my heartfelt gratitude to the many people that have generously given their time, knowledge and support to me throughout the completion of this thesis.

I am greatly indebted to all the interview and focus group participants who took the time to share their thoughts and experiences on life in the City of Edmonton.

I would also like to recognize the considerable assistance provided by Gord Stewart and Daniel Johnson. Your experience working with Aboriginal people in Edmonton proved invaluable, and I appreciate the insights and advice you provided me with throughout my research process.

Last but not least, I would like to thank Leena Kang, Anne Haggerty, Maggie McPherson and Fatema Jamaly for their considerable emotional support throughout this process. I am eternally grateful for the numerous phone calls, Skype dates, late night coffee runs and kindness you have all shown me. 


\section{Table of Contents}

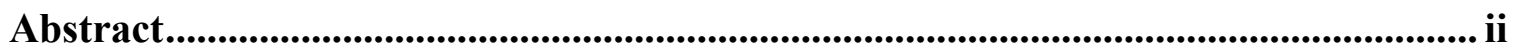

Acknowledgements ......................................................................................................ii

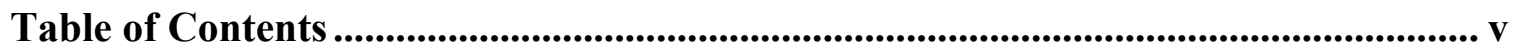

List of Appendices.................................................................................................ii

Introduction ........................................................................................................................... 1

1 Chapter: Classical and Colonial Discourses and Contemporary Indigenous

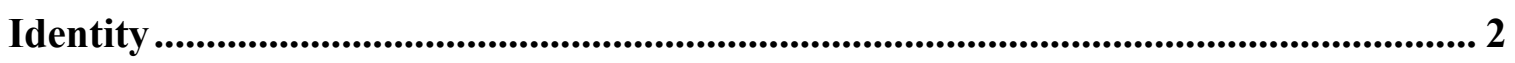

$1.1 \quad$ Classical and Colonial Discourses of Indigeneity ……………....................................

1.2 Urban Aboriginality - Trends and Characteristics ......................................................11

1.3 Characteristics of an Urban Aboriginal Population .................................................. 12

1.3.1 Social and Economic Marginalization ………………………………………….... 12

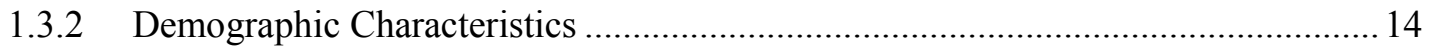

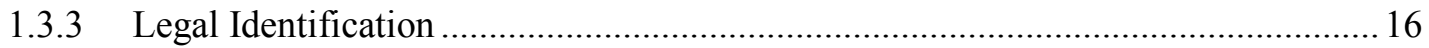

1.3.4 Hyper-mobility or transnational character ……………………………………...... 17

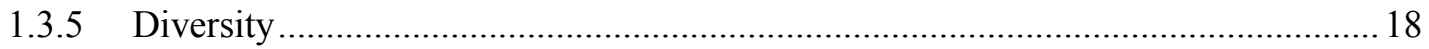

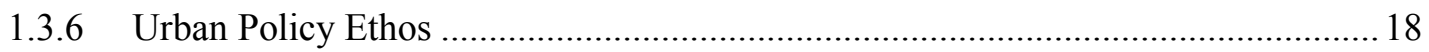

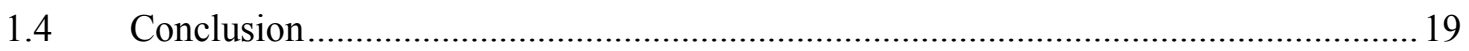

2 Chapter: Methodology and Case Selection............................................................... 20

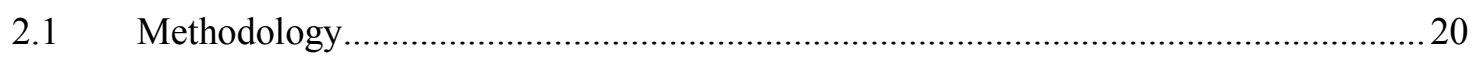

2.1.1 Independent \& Dependent Variables ................................................................2

2.1.2 Data-gathering Techniques ..............................................................................2

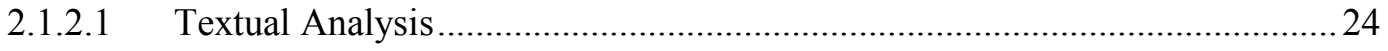

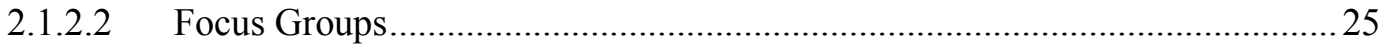

2.1.2.3 Semi-Structured Key Informant Interviews …………................................2 


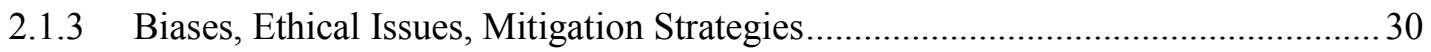

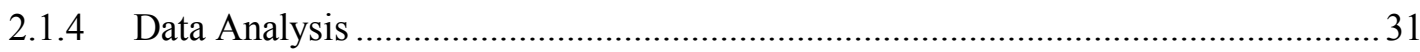

2.2 Case Selection: Characteristics of the Aboriginal Population in Edmonton .................32

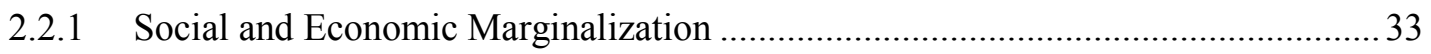

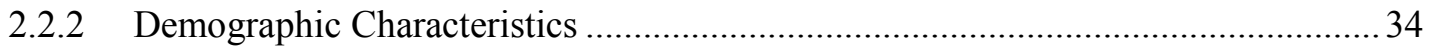

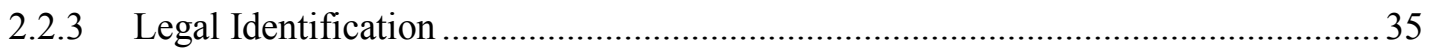

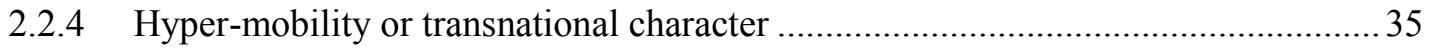

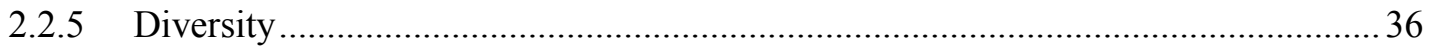

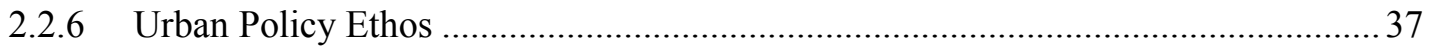

2.3 Selecting the Downtown, Boyle Street and McCauley Neighbourhoods ..................... 37

3 Chapter: Theory and Relevant Research ....................................................... 40

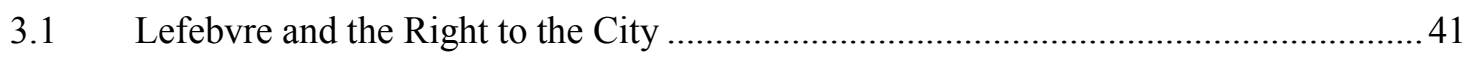

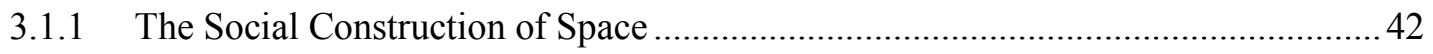

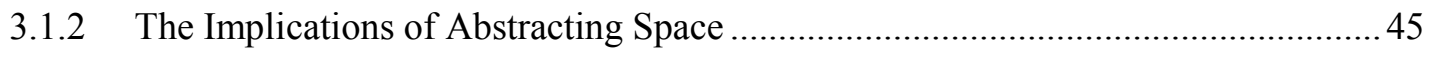

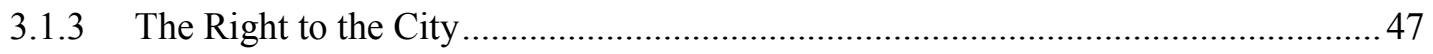

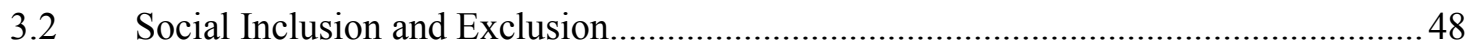

3.3 Relationship between Social Inclusion and the Right to the City .............................50

4 Chapter: Perspectives on Aboriginal Inclusion and Access to Public Space ...... 52

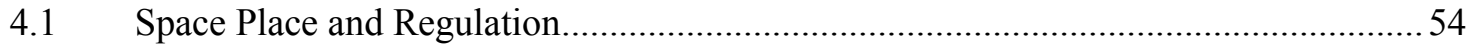

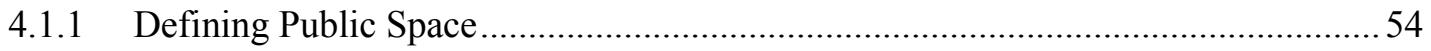

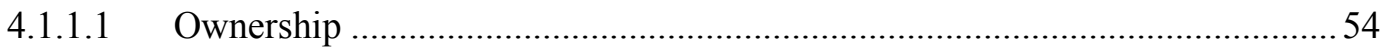

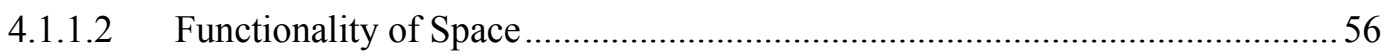

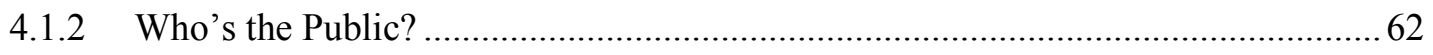

4.1.2.1 Labeling the Public: Client, Customer, or Community Member......................63

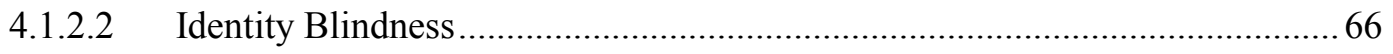

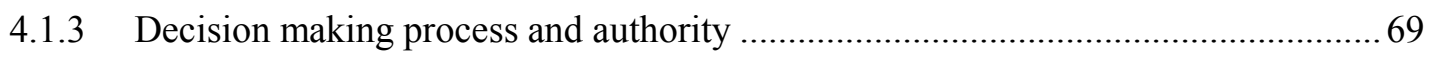


4.2 Appropriating Public Space: Stories of Inclusion and Exclusion.

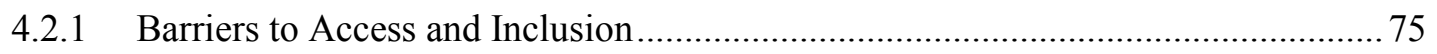

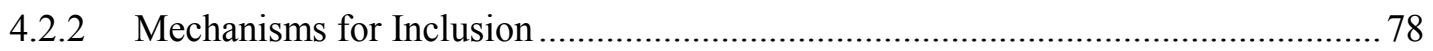

5 Chapter: Conclusion and Recommendations................................................... 80

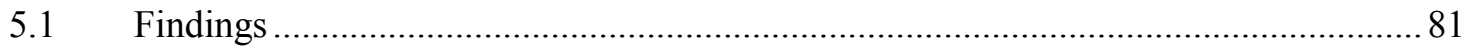

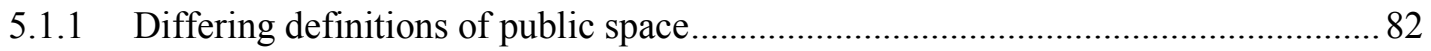

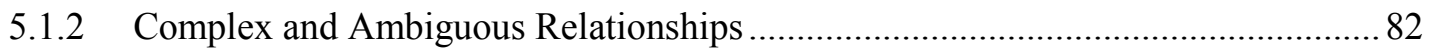

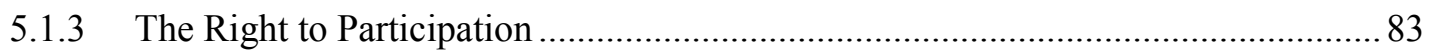

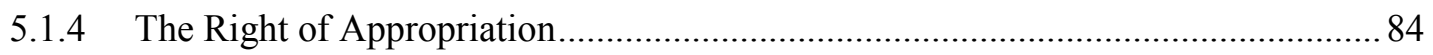

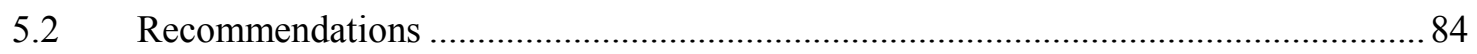

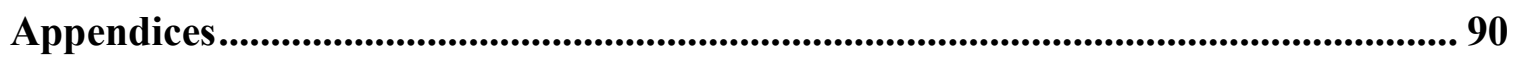

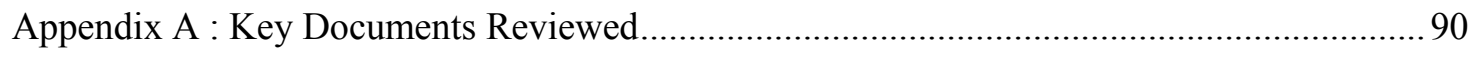

Appendix B : Focus Group Facilitation Guide ............................................................. 91

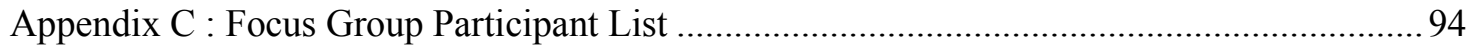

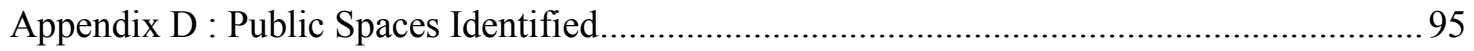

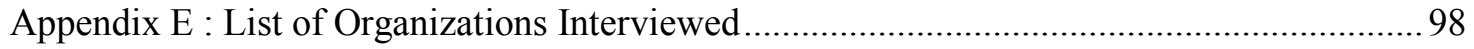

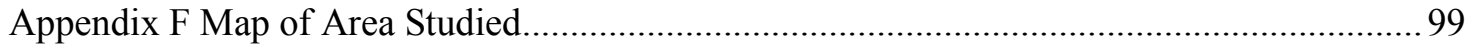

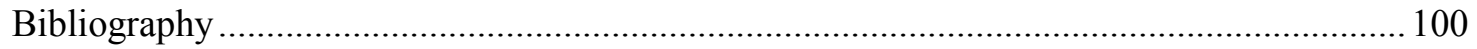




\section{List of Appendices}

Appendix A: Documents Analyzed......................................... 90

Appendix B: Focus Group Facilitation Guide............................... 91

Appendix C: Focus Group Participant List.................................. 94

Appendix D: Public Spaces Identified... ...................................... 95

Appendix E: Organizations Interviewed.................................. 98

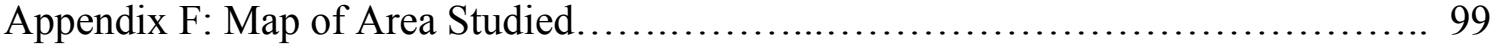




\section{Introduction}

This work utilizes a multidisciplinary approach that applies theoretical concepts from human geography, sociology and political science to the study of urban Aboriginal communities. In particular, the concept of social inclusion, as articulated by French Social Action Secretary of State, Rene Lenoir and authors such as Atkinson (2000), Barata (2000), Du Toit, (2004), Davies(2005) and Burchardt, Le Grand, \& Piachaud (2002), will be combined with Lefebvre's (1991) ideas of the right to the city. The purpose of this work is to explore how access to public space impacts the levels of exclusion and inclusion experienced by Aboriginal people in the City of Edmonton; discuss the challenges Aboriginal people face in accessing urban space to support the creation, maintenance and expression of their identities and culture; and highlight the manner in which Aboriginal people are appropriating and constructing spaces of cultural resilience and safety within the urban environment. The findings from this study support the need for the Aboriginal community, the City of Edmonton and Community Service Organizations to engage in dialogue on the accessibility of public space, particularly the level of decision making authority on the regulation and management of space afforded to Aboriginal peoples, and its impact on the social inclusion of Aboriginal peoples.

In order to do this, this thesis is structured as follows: Chapter 1 discusses the historical discourse and colonial representations of Aboriginal peoples that has contributed to the conceptualization of Aboriginal people as "out of place" in urban society and provides an overview of the characteristics of the urban Aboriginal population. Chapter 2 outlines the methodology employed within this study and provides a rationale for the selection of the City of Edmonton as an appropriate case study for this 
investigation. Chapter 3 provides a brief overview of Lefebvre's (1991) work on the right to the city and focuses on defining and conceptualizing the theoretical concepts of social inclusion and exclusion. The chapter also articulates the relationship between social inclusion and access to public space. Chapter 4 considers the accessibility of key public spaces within the neighbourhoods identified in the research design. This discussion will be informed by interviews with key informants from community service agencies, the City of Edmonton Police Service and City of Edmonton government officials. The chapter also considers the results of focus groups conducted with community members and highlights their perspectives on inclusion and the accessibility of public space. Lastly, Chapter 5 concludes this discussion of inclusion and access to public space, highlights key findings, and provides recommendations to inform the policy and decision making process of community service organizations and the municipal government in the City of Edmonton.

\section{Chapter: Classical and Colonial Discourses and Contemporary}

\section{Indigenous Identity}

"An Indian Reserve in the middle of a big city is an anachronism ... a city is no place for the primitive wards of the government." (Editorial published in The Province - 1943) ${ }^{1}$

The construction of discourse that considers indigenous identity as incongruous with urban space has historically been used to justify the conceptual and physical removal of indigenous people from urban spaces and reinforce the association of

\footnotetext{
${ }^{1}$ As cited in Stranger-Ross, 2008
} 
authentic Indigenous identities with rural locations (Peters 1996; Razack, 2002;

Lawrence 2004; Proulx 2006; Borrows 2008). Despite the work by authors such as Proulx (2003), Lobo and Peters (2001), Fixico (2000), Howard-Bobiwash (2003), and Sanderson and Howard-Bobiwash (1997) to identify and highlight the historical presence of Indigenous peoples in urban environments, and the contemporary reality of cities as Indigenous places, as discussed in Shorten (1991), Silver (2006) and Wilson and Peters (2005), this association of authenticity of culture with non-urban residence continues to de-legitimize the identities, culture and lifestyle of urban Indigenous communities (Borrows, 2000; Peters, 1996). In this chapter, I consider the influence of colonial and classical thought on the conceptual understanding of Indigenous peoples and their place in modern society, in order to demonstrate that the socio-spatial order which marginalizes Indigenous peoples from city-life is premised on the classical philosophical definition of humanity. This chapter also considers and identifies the key elements that characterize the urban Aboriginal experience.

\subsection{Classical and Colonial Discourses of Indigeneity}

The representation of Aboriginal peoples as primitive stems from classical and Enlightenment era philosophical thought that defined the human condition according to its fundamental difference from that of animals. Greek Philosophers, known as the Stoics, were amongst the first scholars to define human identity as the possession of characteristics that are in opposition to those perceived as animalistic (Anderson, 2000). The primary argument within the Stoic narrative of animal-human difference was human 
agency, characterized by the ability to improve or subjugate nature through the cultivation of animals and plants (Anderson, 2000).

In the Nicomachean Ethics, Aristotle introduces the notion of a subhuman condition used to refer to individuals that are technically human but "incapable of reasoning and [who] live a life of pure sensation, like certain tribes on the borders of the civilised world" (Ethics 1149 A9-A12²). This conceptual understanding of indigenous peoples as sub-human creatures was influential to the Enlightenment era thought of natural historians, such as Carl von Linne (1707 -78) and Comte de Buffon (1707 -88) who developed the Great Chain of Being' system, which classified all objects of existence according to the Enlightenment understanding of the four conditions of the human race (Anderson, 2000). According to these scholars, the four human conditions include: the hunter gatherer defined as the most primitive and thus closest to nature, followed by the pastoral society, then the agricultural society and lastly the commercial society (Meek, $1976^{3}$ ). This focus on the capacity of humanity to transcend nature contributed directly to the Eurocentric model of human development as an ascent out of savagery, and led to conceptions of social hierarchy through the discursive production of social groups identified by their "proximity to nature, infantility, eroticism and absence of civilised manners" (Anderson, 2000, p.302). According to this understanding of humanity, Indigenous peoples were represented as "nature in human form" (Francis, 1992; Goldie, 1989; McClintock, 1995) and thus conceived as "prehistoric, atavistic and irrational" (McClintock, 1995, p. 40).

\footnotetext{
${ }^{2}$ As cited in Anderson, 2000

${ }^{3}$ As referenced in Anderson, 2007
} 
Furthermore, Ancient Greek scholars such as Lucretius and Dicaearchus argued that the growth of civilization was a process, a slow progression from a pre-political state where 'primitive man' lived an 'unordered and bestial life' (Lucretius, cited in Blundell, 1986, p. 86) to one where Man not only transcends the primal struggle for survival, but is temporally removed from it through the creation of city-states (Anderson, 2000). In other words, civilization or humanity for ancient scholars was characterized by not only the subjugation of nature, but also the creation of a spatial order.

This understanding of space was influential in the development of policies utilized by colonial governments to facilitate the dispossession of indigenous peoples. As Smith and Godlewska (1994) explain, colonialism is fundamentally about "the transfer of land from one people to another" (p.2), and as such it is essentially a spatial project (see also Said, 1994, p. xxi-xxii). Within colonialism, the perpetuation of discourse that presented Aboriginal peoples as "primitive" was used to justify the transfer of land from Aboriginal peoples to settler society and led to the establishment of reserves as "separate and bounded places for indigenous peoples" (Wilson \& Peters, 2005), "defin[ing] two primal spaces, one for Native people and the other for virtually everyone else" based on a “...racialized juxtaposition of civilization and savagery"” (Harris 2002, p. 265-2684). This division between civilized settler space, represented by cities, and "Native space" represented by reserves contributed significantly to the perception that Indigenous peoples were 'out of place' in urban environments (Hamer, 1990; Peters, 2002) and resulted in the physical removal of Aboriginal peoples from the city landscape.

\footnotetext{
${ }^{4}$ As cited in Wilson \& Peters, 2005
} 
There are several examples of institutionalized, state sponsored mechanisms used to enforce the separation of Aboriginal peoples from urban space, such as the City of Vancouver's attempts to eliminate the Musqueam, Tseil-Watuth, and Squamish Nations from Stanley Park (Blomley, 2004), the City of Victoria's removal of Songhees Indians from the city boundaries in 1911 (Stranger-Ross, 2008), the destruction of Papaschase Cree reserve outside the City of Edmonton (Leonard, 2002; Raby, 1973, p. 39 - 40), and the introduction of the 1885 pass system that required First Nations individuals to obtain permission from the Indian agent before they left their reserves (Barron, 1984).

In many cases, the physical removal of Aboriginal peoples from cities and the enforced separation of Aboriginal and settler communities was justified by a paternalistic desire to protect Aboriginal peoples, informed by a colonial discourse that presented Aboriginal peoples as existing in "anachronistic space...inherently out of place in the historical time of modernity" (McClintock, 1995, p. 40) and thus easily corrupted by city lifestyles. As the Department of Indian Affairs (1911) explained, the decision to relocate the Songhees Indian Reserve is favourable because "such a situation, apart altogether from its accompanying irritation, is fraught with great danger to the Indians" (p. $\left.\mathrm{xxi}^{5}\right)$.

This conceptualization of Aboriginal culture as incompatible with metropolitan centres of society is being challenged by the continued urbanization of Aboriginal peoples. From the 1950's, the Aboriginal population in Canada has become increasingly urbanized with the sharpest increase in urban populations occurring between 1970 and 1980 (Peters, 2005). Statistics Canada (2006) reports that currently over 57 percent of all

\footnotetext{
${ }^{5}$ As cited in Wilson \& Peters, 2005
} 
Aboriginal people reside off reserve, with the majority concentrating in major urban centers including Winnipeg $(68,380)$, Edmonton $(52,100)$, Vancouver $(40,310)$, Calgary (26,575), Toronto $(26,575)$, Saskatoon $(21,535)$ and Regina $(17,105)$.

At the same time, several scholars have worked to combat the negative perception of Aboriginal urbanization as a rejection of traditional culture and highlight the manner in which Aboriginal peoples in urban environments have created strong communities that support the core elements of Aboriginal identity, including: "spirituality, language, land base, values and tradition, family and ceremonial life" (RCAP, 1996, 533). Academics such as Proulx (2003), Lobo and Peters (2001), Fixico (2000), Howard-Bobiwash (2003), and Sanderson and Howard-Bobiwash (1997) have all actively documented the histories of urban Aboriginal communities and demonstrated Aboriginal historical presence in urban areas in order to combat the conceptual separation of native and settler space. In addition, authors such as Shorten (1991), Silver (2006) and Wilson and Peters (2005) have collected and presented vivid accounts of Aboriginal peoples living in cities like Edmonton, Winnipeg and Ottawa and refuted the notion that an urban identity is inconsistent with an Aboriginal identity ${ }^{6}$.

Moreover, authors like Sahlins (1999) argue that culture is not static, rather it responds to external circumstance and people's perceptions of their existence to create a process where "cultural continuity...appears in and as the mode of cultural change" (494). Sahlins (1999) uses this understanding of cultural continuity to assert that as Indigenous peoples interact with market commodities, other cultures and international economic processes they create cultural continuity by adapting and assimilating aspects of other

\footnotetext{
${ }^{6}$ See also Graham \& Peters (2002); Peters (2002a); Peters (2002b); Peters (2001); and Peters (2005)
} 
worldviews into their own. This enables them to "indigenize modernity", develop their own cultural orders and create their own place within the world order.

Despite the population trends and the work being done by these scholars, historical understandings of what it means to be Aboriginal, combined with dominant conceptualizations of Aboriginal culture, continue to negatively impact the contemporary experiences and identities or urban Aboriginal residents by associating "authentic" indigenous identities with non-urban spaces (Buddle, 2011; Francis, 1992; Mandel, 1987; Peters E. J, 2002). In addition, government policies and administrative structures continue to reproduce and reinforce the division between reserves as 'appropriate or authentic' spaces of First Nations culture and cities, as settler space (Tomiak, 2011; Sterritt, 2007). Under the Indian Act, the federal government has obligations to provide social services to First Nations communities. In the early 1950s however, the federal government developed the position that federal constitutional responsibility and the obligation for service provision was restricted to registered First Nations people residing on-reserve (Peters , 2001b; Reeves \& Frideres, 1981). This delineation of reserve and non-reserve identity erodes the historical political relationship Aboriginal peoples have with the federal government, and suggests that authentic Aboriginal identities are found on reserve only.

Policy makers and journalists also largely subscribe to this misconception of the incompatibility of Aboriginal culture with city life, and thus interpret Aboriginal people's decision to urbanize as a rejection of Aboriginal culture and a desire for integration or assimilation (Weston, 1996; Francis, 1992; Harding, 2006; Johnston, 1987; Proulx, 2011). This perspective was also shared by the first generation of academics (Goldie, 
1989; Nagler, 1973; Denton, $1970^{7}$ ). For this reason, much of the literature on Aboriginal urbanization focuses on a consideration of social issues facing Aboriginal peoples in cities, such as poverty, alcoholism, and homelessness and uses the presence of these issues as justification for the argument that Aboriginal culture presents a major barrier to success in adapting to city life (Norris, Clatworthy and Peters, 2013). In other words, Aboriginal people experience what Henry and Tator (2000) refer to as "democratic racism". Success and failure in cities is defined according to settler ideology, with success being gauged in terms of assimilation. This perspective ignores systemic issues of colonialism, discrimination, racism and underfunding, and attributes the existence of social problems to a failure of Aboriginal peoples to transition from " 'simple' to ‘complex' society” (Sahlins, 1999, p. 8; Howard, 2004).

A clear example of the continued existence of democratic racism is recounted by Buddle (2011) who describes an advertisement offering a "free Native extraction service" that was placed and then subsequently removed from the Winnipeg Free Press in March 2010. As Buddle (2011) describes:

"Depicting Native youth as vermin like "pesky little buggers hanging outside your home, in the back alley or on the corner', the ad writer positions Native youth as both subhuman and as belonging more properly to the wilderness. It proposes 'free extraction services to relocate them to their habitat"' (p. 180)

Further examples of this phenomenon are also found in the word choice employed by journalists such as John Stackhouse who refers to "The Indian Beat - a square mile of reckless inebriation" in his investigative series titled "Canada's Apartheid?" (Proulx,

\footnotetext{
${ }^{7}$ See also Stanbury (1975) and Breton \& Akian (1978)
} 
2006) and in the media coverage of missing and murdered women analyzed by Jiwani and Young (2006) who argued that even though only 39 of the 67 missing women are Aboriginal, the media coverage of these women consistently emphasized their Aboriginality and conflated this identity with prostitution. This discursive mechanism further entrenched the view that these women were responsible for their disappearance because they "were located beyond the pale of civilized society - peripathetic wanderers forever in search of the latest fix" (Jiwani and Young, 2006, p. 898). As Pratt (2005) explains these women were perceived as "merely transient, en route to their legislated 'camp', which is the Indian reserve" (p.1059).

As these examples demonstrate, Aboriginal identity and culture continue to be perceived as out of place in urban environments and used to disregard the structural forces that marginalize Aboriginal peoples in urban areas. For this reason, it is important for academics, activists and policy makers to recognize the prevalence of this "democratic racism" and work to develop scholarship, community movements and policies that highlight the continuity and strength of Aboriginal culture in urban space and the role Aboriginal peoples play in urban sustainability. Through this work, this author aims to lend her voice to the celebration of Aboriginal cultural identity in the City of Edmonton. 


\subsection{Urban Aboriginality - Trends and Characteristics}

According to Bollman \& Briggs $(1991)^{8}$, the urbanization of Aboriginal peoples has occurred for similar reasons as the 1921 to 1931 mainstream Canadian urbanization process that transformed Canada from a rural to an urban society ${ }^{9}$. From 1960 onwards, Canadian urban centres have held the majority of the Aboriginal population (Bollman \& Briggs, 1991). However, the degree of urbanization amongst First Nations, Métis and Inuit communities varies considerably. According to Norris \& Clatworthy (2011), nonstatus Indians are the most urbanized (74.5 percent), followed by Métis (69.2 percent), registered Indians (40.4 percent) and Inuit (36.8 percent) ${ }^{10}$.

Even though Aboriginal urbanization has followed mainstream migration patterns, and urban Aboriginal people constitute a visible minority population in cities, they cannot be grouped with other minorities (Nagler, 1970). This is because Aboriginal communities have a specific historical and political relationship with the federal and provincial governments that other minority groups do not possess. At the same, Aboriginal peoples in urban areas display a number of unique characteristics such as cultural diversity, socio-economic heterogeneity, hyper-mobility, and variable attachment to the "urban community" both culturally and politically, that Andersen (2013) argues create an "urban Aboriginality identity largely distinct from those of northern, rural, or reserve Aboriginal communities” (p. 47). In this chapter I would like to consider and

\footnotetext{
${ }^{8}$ As referenced in Williams, 1997. Bollman and Briggs (1991) outline the push and pull factors that influence migration.

${ }^{9}$ It is important to note that the data being referenced by Bollman \& Briggs (1991) consists largely of data gathered from First Nations communities and thus does not necessarily represent the realities of urbanization for Métis and Inuit communities.

${ }^{10}$ Norris \& Clatworthy (2011) utilize data from the 2006 Census within their analysis.
} 
identify the key elements that characterize the urban Aboriginal experience. The key elements will then be used in Chapter 2 to provide a rationale for the selection of the City of Edmonton as an appropriate case study for consideration.

\subsection{Characteristics of an Urban Aboriginal Population}

This section of chapter one aims to identify the six key characteristics that distinguish urban Aboriginal communities from their reserve based counterparts and from other urban visible minority communities.

\subsubsection{Social and Economic Marginalization}

Even though income levels amongst Aboriginal peoples are rising and there is a growing Aboriginal middle class (Wotherspoon, 2003), Aboriginal people residing in urban areas are more likely to exhibit lower socio-economic indicators than their nonAboriginal neighbours (Wilson \& Macdonald, 2010) ${ }^{11}$. As Peters (2007) explains "even though [Aboriginal peoples] participation rates are similar [to those of non- Aboriginal peoples] ...a smaller portion [of Aboriginal people] earn good incomes, unemployment rates are much higher, and a smaller proportion are in managerial, supervisory and professional occupations" (9). Siggner (2003), Stokes et al. (2004) and Silver et al. (2008) further note that urban Aboriginal communities suffer disproportionately from

\footnotetext{
${ }^{11}$ Wilson \& Macdonald (2010) utilize data from the 2006 Census to demonstrate the continued existence of income inequality between Aboriginal and non-Aboriginal peoples in Canada. According to these authors, non-Aboriginal people in urban settings earn \$7,083 more that similarly qualified Aboriginal people. The study also finds that non-Aboriginal Canadians in rural areas make approximately $\$ 2,000$ a year more than urban Aboriginal workers. This demonstrates that the income gap between Aboriginal and non-Aboriginal workers cannot be explained by location alone.
} 
poor health indicators, higher rates of single parenthood, domestic violence and homelessness, lower levels of education, and greater dependence on government support. Silver, et.al (2006) studied the Aboriginal community in Winnipeg and found that Aboriginal people regularly expend a higher proportion of income on rent and reside in environments with high levels of household crowding.

It is important to note that all Aboriginal residents of urban areas do not exhibit these characteristics of social and economic marginalization. Rather, Witherspoon (2003), Peters (2006), Hull (2001), Lawrence (2004) and Newhouse and Peters (2003) utilized data gathered through census records and the Aboriginal Peoples Survey to demonstrate the presence of a growing urban Aboriginal middle class, a finding confirmed by the Ontario Urban Aboriginal Task Force's final report which found that a quarter of its respondents reported incomes of $\$ 40,000$ per year.

Additionally, marginalization is not an exclusively urban phenomenon (Groves, 1999; Wilson \& Macdonald, 2010). Indigenous peoples across Canada have experienced social, economic and political marginalization (Tomiak, 2013; Peters E. J., 2001). Thus it is important to ensure that discussions of the social disadvantages experienced by urban Aboriginal peoples are grounded in a contextual discussion informed by historical understandings of colonialism and the dispossession of Aboriginal lands (Peters E. J., 2001). In other words, it is important to ensure that the history of colonialism, and the continued legacy and impact of residential schools and the discriminatory practices of the Indian Act are recognized within discussions of the current socio-economic disadvantages faced by Aboriginal peoples in Canada. 


\subsubsection{Demographic Characteristics}

The urban Aboriginal population displays different demographic characteristics from the non-Indigenous population. According to the 2011 National Household Survey (NHS), the Aboriginal population in Canada is young, with over a quarter (28 percent) of the population consisting of children under the age of 14. Additionally, Aboriginal youth aged 15 to 24 represent approximately 18 percent of the Aboriginal population and almost 6 percent of the entire Canadian youth population. These national age trends are replicated in urban environments, where approximately 28 percent of the urban Aboriginal population is under 15 years old (Aboriginal Affairs and Northern Development Canada, 2010).

Additionally, Aboriginal Affairs and Northern Development Canada (2010) reports that 54 percent of Aboriginal women reside in urban areas compared to 49.5 percent of Aboriginal men. This imbalance in male-female migration patterns could be attributed to a number of factors, including "differential employment; access to social services delivery; and the patriarchal imposition of Indian Act rules and regulations that have devalued the traditional roles of Aboriginal women and forced them out of their First Nations communities and into Canada's cities" (Peters, 2008, p. 349; Lawrence, 2004; Peters 2000; Peters, 1995).

Considering the place of Aboriginal women in urban environments is important because they are typically amongst the most vulnerable of the city's urban population and suffer a disproportionate amount of the endemic poverty, social, and economic 
marginalization that characterizes many urban Aboriginal communities (Jaccoud and Brassard, 2003; Williams, 1997) ${ }^{12}$.

Furthermore, according to several scholars, Aboriginal women experience high rates of violence within mainstream society and indigenous communities. Indian and Northern Affairs Canada (1996) reports that First Nation women between the ages of 2544 are five times more likely to experience death due to violence than non-First Nation women. These findings are validated by Brennan's (2011) finding that Aboriginal women were three times more likely to report being violently victimized. It is important to note here that in addition to domestic violence and high rates of spousal abuse, by Indigenous and non-Indigenous partners, Aboriginal women also suffer from stranger violence, perpetrated mainly by non-indigenous men. The cases of close to 600 Indigenous women and girls who have gone missing or been murdered in the last 20 years is a clear example of this form of violent victimization (Native Women's Association of Canada 2010).

However, it is important to note that the identity and place of Aboriginal women in urban areas is not exclusively characterized by violence and victimization. Rather, as the Urban Aboriginal Task Force 2007 (UATF, 2007) reports Aboriginal women are more likely to be involved in decision making positions within urban Aboriginal institutions. Loxley and Wein (2003) support this assertion and demonstrate that in Winnipeg, Aboriginal women have been actively involved in the establishment of child

\footnotetext{
${ }^{12}$ It is important to note here that the socio-economic circumstance of Aboriginal women is not easily generalized. This is because the socio-economic indicators of relevance to Aboriginal women do not all point in a single direction. For example, Aboriginal women are more likely than their male counterparts to possess some form of post-secondary education, and also experience lower levels of unemployment. However, at the same time Aboriginal women have a higher incidence of violent death compared to nonAboriginal women, experience higher rates of suicide and are more likely to suffer from lower health outcomes (see Statistics Canada, 2006 for more information).
} 
care and cultural facilities, shelters for women and children, training centres and health care facilities. Krouse and Howard (2009) echo this statement and remind us of "the central role of Indian women in generating and sustaining community cultural and social life" (p. ix). Scholars such as Krouse and Howard (2009), Janovicek (2009), Silver et. al (2006), and Howard-Bobiwash (2003) all document indigenous women's "incipient" and "low-profile" activism in urban space, characterized by a focus on the creation of safe spaces, educational opportunities, and appropriate services for Indigenous families in urban areas.

\subsubsection{Legal Identification}

Legal categorizations of Aboriginal peoples in Canada are a largely spatial designation identifying individuals according to "status", based on their ability to live on, and expect benefits from, reserve communities. Unlike the reserve context, where communities are culturally homogeneous, land based and constitutionally recognized, Aboriginal people living off reserve in the urban environment reflect a complex mix of status Indian bands, Registered Indians who do not belong to bands, treaty Indians, nontreaty Indians, Métis, Inuit, and numerous cultural groups resulting from inter-marriage.

This differentiation according to legal status has been reported to result in discrimination based on perceived and actualized legal hierarchies. The UATF (2007) report recounts "experiences of internal racism on the basis of whether one has Status or not...and/or whether one has links to a First Nation community" (p.21). This legally based discrimination has also been found to intersect with gendered considerations, which has 
resulted in discrimination against Aboriginal women on the basis of their Bill C-31 Status (Lawrence, 2004).

\subsubsection{Hyper-mobility or transnational character}

Canada's urban Aboriginal population exhibit high rates of mobility and are often referred to as "circular migrants" (Trujano, 2008, p. 35). As Aboriginal Affairs and Northern Development Canada (2010) reports, one in four urban Aboriginal people moved residential locations within the year prior to the 2006 Census. These fluid mobility patterns, often referred to as the "churn", blur the rigid reserve-off reserve , or rural-urban categorization of Aboriginal people (Harris 2002; Cardinal 2006; Norris and Clatworthy, 2003). As Peters (2004) explains, Aboriginal people are "stretching out social relations and identities across urban and rural space” (p. 256).

This hyper-mobility is ascribed to the complex interaction between push and pull factors, such as the existence of personal and institutional networks, housing, employment, and education that all impact the migration decisions of Aboriginal peoples both to and from urban environments and their experience in urban areas (Cooke and Belanger, 2006; Graham and Peters, 2002; Distaslo, J. et al, 2004).

Furthermore, Wilson \& Peters (2005) studied the migration of the Anishinabek people from reserves in the Ottawa valley to Toronto, Hamilton and Sudbury and found that the Anishinabek migrants exhibit characteristics of transnational migrants "exploiting the city for economic purposes while at the same time looking to the reserves in terms of ideology, cultural identity, and social ties" (p. 406). These findings concur with the argument made by Hall (1995) who suggests that the Aboriginal diasporas 
operate in a similar logic as other international diasporas. For this reason, conceptually separating urban and non urban geographical and social spaces misses an important component of contemporary Aboriginal identity.

\subsubsection{Diversity}

Aboriginal peoples in Canada are culturally and linguistically diverse. According to the 2006 Census, there are currently 615 First Nations communities and approximately 60 Aboriginal languages spoken across Canada. In the Province of Alberta, for example, there are 46 separate Indian bands with distinct cultural differences emanating from their identification as Blackfoot, Blood, Stony, Cree, Dene, Sault-eaux, or Beaver (Dempsey, 1988). In each case, the community exhibits its own unique culture and language. The impacts of intermarriage, which often results in individuals carrying or identifying with more than one cultural identity also contributes to the diverse nature of Aboriginal communities. This diversity is also present with the urban context, as migrants arrive from a wide range of reserves, settlements, smaller cities and rural communities.

According to the 2006 Canadian Census, approximately 50 percent of the urban Aboriginal population in Canada is comprised of First Nations peoples, of whom an estimated 68 percent are registered under the Indian Act. Additionally, 43 percent of urban Aboriginal people identify as Métis (Statistics 2006a, 43-44).

\subsubsection{Urban Policy Ethos}

Under the Indian Act, the federal government has obligations to provide social services to First Nations communities. The federal government, however, has restricted 
their responsibility by providing services to on-reserve individuals only (Reeves \& Frideres, 1981). Thus, as individuals migrate off reserves and into urban areas they access provincial and municipal services, placing greater demand on provincial and municipal resources. This leads to jurisdictional disputes between the provincial and federal governments over funding, service provision and responsibility for urban Aboriginal peoples (Hanselmann, 2001). It has also resulted in a historically rooted policy coordination vacuum, as provincial and municipal entities have attempted, on an ad-hoc basis, to fill the gap left by federal withdrawal of services. In many cases, this policy coordination vacuum has meant that Aboriginal people residing in urban areas are not able to access the same level of services as reserve based First Nations or as other nonAboriginal Canadians (Hanselmann \& Gibbins, 2003). In order to address this policy and service delivery gap, a number of urban service delivery mechanisms have been created, including several urban Aboriginal institutions that provide culturally appropriate services and work to improve the political, social and economic conditions of the Aboriginal community (Andersen \& Strachan, 2012).

\subsection{Conclusion}

This chapter provided a brief overview of the classical discourse that impacted the historical experience of Aboriginal communities in Canada, and contributed to the creation of a spatial order that presented Aboriginal culture as incompatible with urban space. The chapter also introduces the work of several authors such as Peters (2005), Wilson and Peters (2005), Proulx (2003), Lobo and Peters (2001), Fixico (2000), Howard-Bobiwash (2003), Sanderson and Howard Bobiwash (1997), Shorten (1991), and 
Silver (2006) who highlight the historic and continuous presence of Aboriginal peoples in urban environments. This consideration of literature on the experience of urban Aboriginal peoples, and the impact of the creation of a spatial order within colonialism, provides context to the investigation and discussion of the impact that access to urban public space has on the social inclusion of Aboriginal peoples in the City of Edmonton. This chapter also identifies the characteristics that define the urban Aboriginal population in order to highlight the urban Aboriginal population as distinct from reserve based populations, as well as socially and economically marginalized visible minority populations in urban environments. These key characteristics will be applied to the City of Edmonton in the next chapter and used to provide a rationale for the selection of the City of Edmonton as a suitable case study for consideration.

\section{Chapter: Methodology and Case Selection}

\subsection{Methodology}

This section outlines the methodological approach utilized within this investigation. It includes the identification and definition of the independent and dependent variables; an overview of the data gathering techniques utilized; a consideration of biases, ethical concerns and mitigation strategies; and lastly a discussion of the process used for data analysis. 


\subsubsection{Independent \& Dependent Variables}

The dependent variable within this study is social inclusion. For the purpose of this study, I will utilize the four dimensions of social inclusion identified by Burchardt, Le Grand, \& Piachaud (2002), conceptualized as follows:

1. Consumption: the capacity to acquire necessary and desired goods and services

○ Capacity to acquire includes: purchasing, foraging, begging, solicitation, pan handling, accessing social assistance and/or the services provided by charitable institution

○ Necessary goods and services include: food, water, clothing, shelter, healthcare, and emergency services

- Desired goods and services refer to items perceived as desirable by the individual. This may include; forms of entertainment such as books, magazines, music, movies, games, as well as alcohol, and recreational drugs; luxury goods such as designer clothing and accessories, electronic devices, delicacy foods; etc.

2. Production: participation in economically or socially valuable activities, as defined by the individual

○ Economically valuable activities include: employment, busking and performance, pan handling, begging, sale of art and crafts, and solicitation

- Socially valuable activities include: production of art (includes graffiti, murals, paintings/sculpture/crafts, whether for sale or not), performance (for money or not), further education and training, etc.

3. Political engagement: involvement in local or national decision-making processes 
- Includes activities such as: attendance at political debates, speeches and public meetings; voting; participation in letter writing campaigns, petitions, protests and rallies; and membership in advocacy groups, non-governmental organizations, and political parties.

4. Social interaction: integration with family, friends and community.

- Includes: hanging out friends or family in public areas (e.g. picnics in the park, shopping, coffee, drinks or meals in restaurants and coffee shops, etc); membership in community leagues, clubs, and recreational facilities; and participation in festivals, civic celebrations, and public holidays.

The independent variable is access to public space. The term public space refers to the usage or perceived usage of the space, rather than the actual ownership (public vs. private). For the purpose of this study a public place is defined as an indoor or outdoor area, either privately or publicly owned, to which members of the public have access by right or by invitation, expressed or implied through the payment of money, consistent usage by the public, membership or residence in a community or club, or the existence of signage, regulation or community norms permitting public usage. This does not include places used exclusively by one or more individuals for private gatherings or other personal purposes. Examples of public spaces include: parks, city centre squares, coffee shops, schools, public libraries, community centers, markets, religious institutions, etc.

It is also important to define access. For the purpose of this study, access refers to the degree to which the individuals and groups who use, work or reside in these spaces can determine and manage what activities take place, who can participate and what 
resources are available. There are three dimensions of accessibility identified in the literature (Pasaogullari \& Naciye, 2004; Ribot \& Peluso, 2003):

- Physical accessibility conceptualized as the ability of all people regardless of identity, age, financial resources and physical capacity to use public spaces. This dimension focuses on the design of the space to ensure it is representative of users. It includes consideration of whether the space has facilities to enable use by a variety of individuals including children, the elderly and individuals with disabilities; what activities and services are available, and whether the aesthetics (e.g. public art installation, murals, gardens, etc.) are reflective of the community of users.

- Spatial accessibility is conceptualized in terms of proximity and dispersion. Proximity considers the distance between residential locations and public spaces, as well as the time required to travel to and from public spaces. Dispersion refers to the placement of public spaces in a manner that ensures every resident is equitably served.

- Social/Political accessibility refers to decision making structures involved in the creation, management and use of public spaces. This includes a consideration of how a public space is designed, how it is designated (regulation, zoning, building code enforcement, etc.), and who decides who does and does not get to use a space and in what ways the space can be used (bylaws, community league membership rules, private business user codes, etc.).

Based on these variables, the following research question is posed within this study: 
○ Does accessibility to public space, particularly physical and social/political accessibility to public space, impact the level of social inclusion, as defined by Burchardt, Le Grand, \& Piachaud (2002), experienced by Aboriginal peoples?

\subsubsection{Data-gathering Techniques}

A mixture of quantitative and qualitative data gathering techniques were utilized in order to complete this research. The purpose of this section is to identify each data gathering technique and provide a rationale for its usage. This section also describes the researchers experience conducting focus group sessions and semi-structured interviews within the community.

\subsubsection{Textual Analysis}

This process included a review of the manifest content of key documents such as the City of Edmonton Parkland Bylaw 2202, barring policies ${ }^{13}$ from community organizations, information from community service organization websites, and reports surrounding the development of key public spaces (e.g. the downtown arena, the Boyle Street Renaissance Quarters project, the McCauley Community Revitalization project) to determine the main issues surrounding public space, who was involved in decision making regarding the public spaces, and how and by whom decisions about current usage and management are being made. This analysis provided information regarding the

\footnotetext{
${ }^{13}$ A barring policy is a policy that provides guidance on measures that can be used to enforce appropriate usage and behaviour within a space. The policy typically identifies a code of behaviour which lists unacceptable behaviours, a process for notifying individuals of violations to the code of behaviour and a process to bar the individual from accessing the space for a period of time subject to appeal.
} 
accessibility dimension of the independent variable, specifically social and political accessibility. The documents reviewed within this process were identified through information gathered from key informant interviews and from the researcher's own survey of online resources. A list of documents examined is provided in Appendix A.

\subsubsection{Focus Groups}

The research design called for the collection of data through a series of focus groups intended to collect qualitative information on the accessibility of public space and its impact on the four dimensions of social inclusion. In order to facilitate this, a focus group facilitation guide with sample questions was developed (see Appendix B). Participants were to be identified through the placement of posters in a variety of organizations that serve the Aboriginal community, as well as in a number of public spaces.

However, after placing a number of posters in a variety of locations I discovered that I was the source of amusement for a number of community members who followed me around the neighbourhood to watch what I was doing. After a couple of days, I was finally approached by a community member who informed me that no one was actually reading my posters. Based on her advice, I invited the six community members who had been following me around to join me for coffee and a snack, and used this opportunity to tell them about my project, ask if they were interested in participating, and if they would be able to pass on information to their friends and family members. Five of these individuals agreed to participate and bring one friend or family member along as well. Over the next few weeks I continued to frequent popular community spaces and was able 
to use the above described approach to recruit a total of 30 community members, which was significantly higher than the number of individuals needed to complete the three focus groups the study design called for ${ }^{14}$.

Focus group participants were divided according to age ${ }^{15}$, based on the assumption that different age ranges utilize spaces and experience inclusion differently. Additionally, the researcher worked to ensure appropriate male and female representation in each session to enable information from both males and females is captured, based on the assumption that males and females utilize public space and experience inclusion in a different manner ${ }^{16}$.

Five focus groups were scheduled from February 10-23, 2014 and held in rooms provided by three community organizations, Boyle Street Community Services, Bissell Centre and Stanley Milner Public Library ${ }^{17}$. However, actual participation was low (only 11 individuals, five between the age 16 to 30 and four aged 45 and over participated ${ }^{18}$ ) because of two key factors. First, focus group sessions were scheduled to occur during the 2014 Winter Olympic Games, and thus individuals interested in viewing particular events chose not to attend a focus group session if the timing conflicted. In addition, the room provided for focus group sessions in the Stanley Milner Library was located on the sixth floor, in an area not commonly used by members of the public. A number of

\footnotetext{
14 The study design aimed to conduct three focus groups with approximately 3 to 5 participants each.

${ }^{15}$ Age 16-30, Age 31-44 and Age 45+

${ }^{16}$ Separating focus groups according to age and gender would have been a preferable mechanism for collecting data on the distinctive social inclusion and exclusion experiences of Aboriginal men and women when accessing public space. However, the limited resources (both financial and time) limited the researcher's ability to pursue this option. In addition, this research does not aim to distinguish between the experiences of Aboriginal men and women or compare them to each other in any way. For these reasons, the use of a mixed gender focus group setting was deemed to be appropriate.

${ }_{17}$ These organizations volunteered to provide room space for the focus groups.

${ }^{18}$ See Appendix $\mathrm{C}$ for a list of focus group participants broken down by age and gender.
} 
participants expressed difficulty locating the room and indicated discomfort in accessing the area, as they did not feel like they were allowed to be in that place ${ }^{19}$. Based on this information the final focus group was scheduled for March 4, 2014, in order to obtain perspectives from individuals aged 31 to 44 . This session was conducted at the facilities provided by Boyle Street Community Services, as participants indicated the greatest degree of comfort at this location. Three individuals participated in this session.

Care was taken to ensure all participants understood the purpose of the research and were aware that focus group participation was voluntary. All participants were required to complete consent forms prior to participation. Participants were provided with a warm drink and snacks during the sessions. In addition, bus tickets were provided to participants upon request.

I facilitated each focus group and took detailed notes ${ }^{20}$. In each session, I introduced the topic and provided a brief description of the intention of the research and then briefly discussed the research question ${ }^{21}$. In contrast to a traditional focus group, where participants feed off each other's ideas while responding to the facilitator's question, individuals within my study opted to follow the etiquette of a talking circle. Each person took some time (approximately five to seven minutes) to speak of their experience living in Edmonton. While an individual was speaking, no one asked

\footnotetext{
${ }^{19}$ This information was useful as it confirmed the need to examine Aboriginal peoples accessibility of public space.

${ }^{20}$ Participants were asked for permission to audio-record sessions, however many of them felt uncomfortable. For this reason, no audio-recordings were made of any focus group sessions.

${ }^{21}$ A sample introduction and overview of research question can be found in the focus group facilitation guide included as Appendix B
} 
questions, commented or otherwise interrupted the speaker ${ }^{22}$. Once each person had spoken, participants waited for me to speak. In each circle I was expected to share my experience and history with life in the city, as well. Once this was complete, participants indicated that the session was complete. In every session participants remained in the room for 15 to 20 minutes after the session to have coffee and chat with me and each other. During this time, I was able to seek out individual participants if I needed further information or clarification on something they had said.

Even though the use of talking circle etiquette within the focus group process was culturally appropriate and thus enabled participants to feel more comfortable sharing personal and often traumatic experiences with each other and the researcher, the lack of active questioning and probing from participants during the session presented some challenges. Firstly, each participant presented a narrative, which was reflective of what they believed was important and did not necessarily answer one of the questions being posed. Thus, it was not easy to determine how the information presented by the participant actually related to their experience accessing public space or the indicators of inclusion presented in the literature. This made the data analysis process more difficult. Also, because each individual presented a personal narrative, they did not always provide responses to the same questions. This made it difficult to compare responses between participants, which would have been a useful mechanism for demonstrating differences between the social inclusion and public space access experiences of various age ranges.

\footnotetext{
${ }^{22}$ It is important to note that even though participants did not comment on each other's narratives out loud, they likely listened to, thought about and accounted for the information provided by others before determining what they would share.
} 


\subsubsection{Semi-Structured Key Informant Interviews}

In addition to the focus groups with community members, semi-structured interviews were conducted with key informants in the community, including a representative from the City of Edmonton Aboriginal Relations Office, a representative from a number of community organizations, and a member of the City of Edmonton Police Service. The community organizations included in this study were selected based on their history of community involvement ${ }^{23}$, their level of interaction with the Aboriginal community ${ }^{24}$ and their relevance as a developer, manager or regulator of public space ${ }^{25}$.

These interviews were used to identify key public spaces within the community; collect documents that may be useful for review; gain perspective on how community service organizations see themselves in relation to the Aboriginal community and understand whether the development, regulation and management of public spaces in the city has changed over the last 10-15 years as the Aboriginal population within the city has grown. Interviews were conducted with 10 community organizations and 3 institutional representatives ${ }^{26}$.

\footnotetext{
${ }^{23}$ The research design only considered organizations that have been serving the community for more than five years. This was done to keep the scope of the research manageable and ensure that the organizations being engaged were able to speak to how the neighbourhoods in question have changed as the Aboriginal presence has increased and development pressure has intensified.

${ }^{24}$ In order to keep the scope of the thesis manageable, only organizations that specifically served members of the Aboriginal community were included.

${ }^{25}$ This criterion eliminated community organizations such as the Canadian Paraplegic Association, Aboriginal housing organizations, drug prevention and treatment facilities, health centres, training societies, etc. Although it can be argued that many of these organizations engage with the Aboriginal community or have influence in the creation and regulation of public space, they are not explicitly involved (with what) and were eliminated in order to ensure the thesis could be completed within the time and resource constraints of the researcher.

${ }^{26}$ See Appendix E for a list of organizations included within this study.
} 


\subsubsection{Biases, Ethical Issues, Mitigation Strategies}

Privacy and confidentiality concerns emerge in all quantitative and qualitative research methods. Thus, in addition to obtaining informed consent from all research participants before proceeding with data collection, community members were given the option of providing permission for use of their first name within the research or selecting an appropriate pseudonym for themselves. Representatives from community organizations were also provided the option of remaining anonymous within the research. In most cases, community members selected a pseudonym for use. Additionally since most organizational respondents from community service organizations requested their input be provided anonymously, all quotations from interviews with individuals representing community service organizations will be referenced as follows:

Representative of Community Service Organization (neighbourhood name), date interview was conducted.

This does not apply to representatives from key municipal institutions such as the City of Edmonton Parks and Recreation Department or the Edmonton Police Service.

Moreover, as a non-Aboriginal researcher, I was aware of the need to be respectful of Aboriginal identity, historical experience and cultural/traditional practices. For this reason, this research abided by the research requirements for studying Aboriginal populations outlined by the Social Sciences and Humanities Research Council (SSHRC) entitled, Tri-Council Policy Statement: Ethical Conduct for Research Involving Humans 
- Chapter 9: Research Involving the First Nations, Inuit and Métis Peoples of Canada ${ }^{27}$; and the Ownership, Control, Access, and Possession (OCAP) standards ${ }^{28}$.

\subsubsection{Data Analysis}

All interviews obtained within this research were transcribed. The focus group sessions resulted in 29 pages of single spaced data. The purpose of these interviews was to obtain community member's perspectives on accessibility to public space and the level of inclusion being experienced. For this reason, the data was categorized according to the three dimensions of accessibility (spatial, social/political and physical) identified in the literature. The data was also categorized according to dimensions of inclusion (production, consumption, political engagement and social interaction). Once these categories were finalized, a thematic analysis was performed on each category in order to create linkages between the narratives of multiple community members.

The semi-structured interviews conducted with Community Service Organizations and other institutional representatives were also transcribed, a process which resulted in with 36 pages of typed- single spaced information. The purpose of these interviews was to obtain information on the creation, management and regulation of public spaces in the City of Edmonton. For this reason, the data was first categorized according to whether it was relevant to creation, management or regulation of public space. As every organization interviewed does not always engage in all three activities, the amount of data in each category varied significantly. The data within each category was

\footnotetext{
${ }^{27}$ Accessible here: http://www.pre.ethics.gc.ca/eng/policy-politique/initiatives/tcps2-eptc2/chapter9chapitre9/

${ }^{\frac{1}{28} \text { Accessible here: } \text { http://www.rhs-ers.ca/node/2 }}$
} 
subsequently organized according to themes, which enables the consideration of linkages between the operations and experiences of multiple organizations.

The interviews with organizational and institutional representatives were also intended to solicit views on engagement with the Aboriginal community. Data pertaining to this topic was identified and then grouped according to themes.

Throughout the term of the research, a variety of textual materials (15

documents $^{29}$ ) were obtained and analysed. In all cases, only the manifest content of materials was considered. These materials were reviewed in order to obtain supplementary information necessary to contextualize the information obtained from interviews. For this reason, information obtained from this analysis will serve a largely supplementary role within this thesis.

To ensure appropriate respect is given to the sharing of personal and community knowledge the findings of the study were made available to the community studied prior to publication. This provided participants with the opportunity to review the findings, provide comments, and correct any cultural inaccuracies. No comments or suggestions were received from participants.

\subsection{Case Selection: Characteristics of the Aboriginal Population in Edmonton}

Aboriginal people have resided in the area known as the City of Edmonton for generations ${ }^{30}$. The City of Edmonton is built on the traditional territory of the Treaty 6

\footnotetext{
${ }^{29}$ See Appendix A for a list of documents analyzed.

${ }^{30}$ The Papaschase Cree nation negotiated a reserve on the southern side of the North Saskatchewan River in what is now south Edmonton. The 241 reserve members were entitled to 124 square kilometers of land on the south side of the river. In 1881 however, settlers began to petition the government to relocate the
} 
First Nations, and was referred to as Amiskwaciy or Beaver Hills by the Cree people. Historically, the Rossdale Flats that comprise the City of Edmonton were an important pehonan, a waiting and gathering place for Aboriginal people (City of Edmonton, 2009). The City of Edmonton has also been the home of a large Métis community, who lived and worked in the Fort Edmonton district, in nearby St. Albert and Lac Ste. Anne and across the territory (City of Edmonton, 2009).

The purpose of this section is to provide a justification for the choice of the City of Edmonton as a useful case for exploration. For this reason, this section begins with a brief discussion of how the City of Edmonton fares in relation to the six elements that characterize urban Aboriginal populations across Canada, identified in Chapter 1. Following this, a rationale for the identification of key neighbourhood's of focus within the study will be provided.

\subsubsection{Social and Economic Marginalization}

Aboriginal people residing in urban areas are often impoverished and exhibit lower socio-economic indicators than their non-Aboriginal neighbours. The population in the City of Edmonton follows this trend. Two in five Aboriginal residents of Edmonton live below the poverty line, and the median income is only two-thirds that of non-Aboriginal residents. This is particularly true for Aboriginal women and even more so for First Nations women. In 2005, the median income of the Aboriginal population in Edmonton aged 15 years and over was $\$ 18,769,33$ percent less than the median income

reserve. On November 19, 1888, at a meeting called with four days' notice by government agent three men signed a surrender document for the entire reserve in south Edmonton. The Papaschase descendants have sued the federal government to settle their land claim. 
reported for the non-Aboriginal population in Edmonton (Statistics Canada, 2006 ${ }^{31}$ ).

Furthermore, according to the Census 2006, 38 percent of Aboriginal people in Edmonton were living in low income households compared to 16.5 percent of nonAboriginal people.

In addition, even though the Aboriginal labour force participation rate in Edmonton is similar to that of non-Aboriginal people (68.6 percent compared to 72.3 percent), the unemployment rate is considerably higher. Aboriginal people in Edmonton experience an unemployment rate of 10.3 percent, compared to 4.6 percent for the nonAboriginal population.

\subsubsection{Demographic Characteristics}

According to Statistics Canada (2006), the Aboriginal identity population in is younger and growing at a faster rate than the non-Aboriginal population. The population in the city of Edmonton reflects these trends. Approximately 50 percent of the Aboriginal population in Edmonton is less than 25 years old, compared to approximately 32 percent of the non-Aboriginal population. Of this 50 percent, 18.1 percent are under the age of five (Statistics Canada, 2009).

Additionally, according to the Aboriginal Statistical Profile released by the City of Edmonton in 2009, the Aboriginal Identity population for the City of Edmonton has grown by 25.7 percent from 2001 to 2006 . This rapid population growth is significant because if the Aboriginal population in Edmonton continues to grow at the same pace, this could result in an estimated 66,094 Aboriginal Identity population living in the City

\footnotetext{
${ }^{31}$ See also City of Edmonton (2009)
} 
of Edmonton by 2018. At that point, Edmonton will overtake Winnipeg as the city with the largest Aboriginal population in Canada.

Furthermore, according to Statistics Canada (2006), approximately 10 percent of the Aboriginal households in Edmonton are single parent households. Of these, 85 percent are headed by females. This finding is consistent with national and provincial trends that found that a significant proportion of the urban Aboriginal population in cities across Canada are comprised of single parent families. These findings are significant because, as Dooley et. al (1998) and Kerr \& Michalski (2014) report, lone parent families are more likely to be low income, reside in inadequate or overcrowded housing conditions, experience lower levels of educational attainment and be subject to higher levels of emotional and psychological stress.

\subsubsection{Legal Identification}

The differentiation of Aboriginal people according to a legal classification based on the association or membership in a reserve based community has implications for Aboriginal residents in Edmonton as well. Thus, even in Edmonton the population of Aboriginal people consists of a mix of First Nations people that are status, non-status, treaty, and non-treaty; as well as Métis, Inuit, and a variety of other groups that have developed as a result of inter-marriage.

\subsubsection{Hyper-mobility or transnational character}

Canada's urban Aboriginal population exhibits high rates of mobility and the Aboriginal population in Edmonton follows this trend. According to Statistics Canada 
(2006), members of the Aboriginal population were more likely to have moved five years prior to the 2006 Census than the non-Aboriginal population (70 percent compared to 49 percent). Of these individuals, 44 percent reported that they had moved within the City, while 26 percent indicated that they had moved from a completely different area.

\subsubsection{Diversity}

As discussed in Chapter 1, First Nations and Metis populations are the most urbanized Aboriginal population in Canada. This trend is also visible in the City of Edmonton. The total population in the City of Edmonton consists of largely Métis people (approximately 3 percent and First Nations people (approximately 2.3 percent). The Inuit population is small consisting of only 0.1 percent.

Because Edmonton falls within Treaty 6 territory, a large number of Aboriginal residents within the city are from the 17 First Nations that are part of that treaty (City of Edmonton, 2009). As such, most First Nations people within Edmonton identify as Cree or Saulteaux, In addition, as the largest northern city in Alberta, Edmonton also absorbs a number of First Nation migrants from Treaty 8 territory in northern Alberta. As such, Edmonton is also home to several Aboriginal people who identify as, Chipewyan, Dene, Beaver, or Blackfoot (City of Edmonton, 2009). In addition, Edmonton receives a number of migrants from the eight Métis Settlements located in northern Alberta (Government of Alberta, 2013). 


\subsubsection{Urban Policy Ethos}

The City of Edmonton has been making an effort to promote collaboration with the Aboriginal community by establishing an Aboriginal Relations Office in 2005, negotiating an Urban Aboriginal Accord ${ }^{32}$, and recently proclaiming August $23^{\text {rd }}$ Treaty 6 Day in Edmonton ${ }^{33}$. In addition, Edmonton is also one of the cities included within the federal Urban Aboriginal Strategy ${ }^{34}$. Despite these positive policy interventions, the Aboriginal policy environment in Edmonton is still characterized by a distinct policy coordination vacuum (Hanselmann, 2001). At the same time, consistent with national trends, Edmonton has experienced a proliferation of Aboriginal institutions that offer culturally relevant services and attempt to address the gaps in policy and service delivery experienced by Aboriginal peoples in urban areas.

\subsection{Selecting the Downtown, Boyle Street and McCauley Neighbourhoods}

The City of Edmonton is divided into 12 Wards consisting of 31 Traffic Districts differentiated by the City of Edmonton Planning and Development Department according to "inner city" and "suburban". Aboriginal people reside in numerous Traffic Districts ${ }^{35}$ across the city, however, in 2006, 62.5 percent of Aboriginal residents reported living in a Traffic District classified as inner city ${ }^{36}$, specifically in North Central, Downtown Fringe, Jasper Place, Beverly and Londonderry. Within these Traffic Districts, the largest

\footnotetext{
${ }^{32}$ For access to the City of Edmonton Aboriginal Relations Office and the Urban Aboriginal Accord, see: http://www.edmonton.ca/city_government/city_organization/aboriginal-relations-office.aspx

${ }^{33}$ For more information see: http://www.edmonton.ca/city_government/news/2013/treaty-6-dayproclaimed-in-edmonton.aspx

${ }^{34}$ For more information see https://www.aadnc-aandc.gc.ca/eng/1389724611277/1389724670841

${ }^{35}$ Aboriginal people in Edmonton reside in 29 of the 31 Traffic Districts in Edmonton.

${ }^{36}$ There are 11 neighbourhoods classified as inner city in Edmonton. They include: the Central Business District, University, Southgate, Jasper Place, North Central, Calder, Londonderry, Beverly, Capilano, Millwoods, and Bonnie Doon.
} 
population is found within the North Central Traffic District (4510 people), followed by Jasper Place (3555), Londonderry (3555) and Downtown Fringe (3470).

The neighbourhoods selected within this study include: Boyle Street Community, McCauley Community, and Downtown. These communities are located in the Downtown Fringe Traffic District, which contains the fourth largest Aboriginal population in the city. This area was selected because it not only represents an area with a significant Aboriginal population, but it is an area that has seen significant gentrification and development over the last 15 years. This is significant because gentrification and development raises property values, typically increases the number of visitors and new residents within a community, and often results in conflict over the use of public space.

The Downtown Housing Reinvestment Grant Program together with the Capital City Downtown Plan ${ }^{37}$ has spurred residential construction in these communities resulting in the creation of approximately 3,900 new residential units (City of Edmonton, 2010). While the availability of additional housing in these neighbourhoods is theoretically a positive impact, these new residential units have largely been the result of high-rise condo conversions. Thus the new dwellings are largely intended to attract high and middle income city residents, rather than meet the housing needs of low income inner city neighbourhoods. The Capital City Downtown Plan calls for the construction of an Entertainment District within Downtown, which has resulted in the construction of Rogers Place (the downtown Arena), and the investment in Capital Boulevard consisting of the construction of Centennial Plaza.

\footnotetext{
${ }^{37}$ Accessible here: http://www.edmonton.ca/city_government/documents/PDF/Capital_City_Downtown_Plan_May 27_2010. pdf
} 
Additionally, in 1994 the Boyle Street/ McCauley Area Redevelopment Plan ${ }^{38}$ was adopted by the City Council. This plan was designed to address the following concerns: poor housing conditions, vacant land and lots that detract from the appearance of the community, high traffic volumes, prostitution, high crime rate, high levels of poverty and unemployment. This plan created the Boyle Street Renaissance ${ }^{39}$ and the McCauley Revitalization Association ${ }^{40}$. While the plan is largely focused on the promotion of community events and the coordination of advocacy to raise key community interests with city officials, the plan does call for the creation of new recreational facilities, improvements to key park spaces, the development of an Aboriginal welcome centre and new affordable housing initiatives. This has led to the development of the Quarters project ${ }^{41}$. In 2010, the City of Edmonton Ten Year Strategic Plan $^{42}$ was also adopted. This plan calls for the transformation of Edmonton's urban form and has led to investments in numerous projects, including the revitalization of Jasper Avenue as a cultural and shopping street.

The confluence of an Aboriginal identity population and the significant revitalization efforts in these three neighbourhoods has resulted in tensions over the accessibility of public space in the neighbourhood ${ }^{43}$, making these locations an excellent

\footnotetext{
${ }^{38}$ Accessible here: http://www.edmonton.ca/city government/documents/Boyle St McCauley_ARP_Consolidation.pdf

${ }^{39}$ For more information see: http://www.edmonton.ca/city government/projects redevelopment/boylerenaissance.aspx

${ }^{40}$ For more information see: http://www.edmonton.ca/city_government/projects_redevelopment/mccauleyrevitalization.aspx

${ }^{41}$ For more information see: http://www.edmonton.ca/city_government/projects_redevelopment/thequarters-downtown.aspx

${ }^{42}$ For more information see: http://www.edmonton.ca/city government/city vision and strategic plan/the-way-ahead.aspx

43 "We normally use Giovanni Caboto Park to host National Aboriginal Day celebrations. This year the McCauley Community League booked the park. They didn't even do anything there that day. They just
} 
case study for consideration. Furthermore the preceding discussion of the key characteristics of the urban Aboriginal population, together with a consideration of how the City of Edmonton`s Aboriginal population fares in relation to those characteristics, provides a clear rationale for the study of how access to public spaces in the Boyle Street, McCauley and Downtown neighbourhoods of the City of Edmonton impacts the social inclusion of Aboriginal residents in those communities and their right to the city.

This chapter provided a detailed description of the research design employed within this study, including an identification of the independent and dependent variables, as well as a comprehensive description of the data gathering and analysis procedures. It also uses the six major characteristics that make the urban Aboriginal population unique, identified in Chapter 1, to demonstrate the suitability of the City of Edmonton as a case study for consideration. The next chapter will provide an overview of the right to the city as defined by Henri Lefebvre (1991) and connect it to the concept of social inclusion and urban space.

\section{Chapter: Theory and Relevant Research}

This thesis is grounded in the work of Henri Lefebvre, a critical spatial theorist whose seminal work, The Production of Space, challenges essentialist notions of space as static and politically neutral ${ }^{44}$. In addition, this work utilizes the body of literature that exists on social inclusion and exclusion, a theoretical concept developed in France in the

\footnotetext{
didn't want us to be there" (anecdote from Representative of Community Service Organization (Boyle Street), Feb/04/2014).

${ }^{44}$ For other authors who offer similar perspectives see: Harvey (2012); (Harvey (2003); Harvey (1973); Marcuse (2002); Mitchell D. (2003); and Soja (2010)
} 
early 1980s by Rene Lenoir and later expanded upon by authors such as Ebersold (1998), Atkinson (2000), Barata (2000) and Du Toit (2004). This chapter begins with a brief overview of Lefebvre's theoretical framework and his conception of urban space. This will be followed by a consideration of social inclusion and exclusion. Lastly, the chapter will consider how these conceptual elements can be interpreted and applied within a discussion of access to public space and social inclusion for Aboriginal peoples.

\subsection{Lefebvre and the Right to the City}

Lefebvre (1991) integrates the spatial and social dimensions of urban development and proposes a materialist analysis "where space is seen as a social product, as well as a means of production" (p. 85). In other words, Lefebvre presents a dialectical history of space in which space is produced through dynamic, multi-dimensional and mutually transformative relationships with human activity. Lefebvre posits that there is a theoretical distinction between the mental or logical conception of space occupied by planners and mathematicians, and "the practico-sensory realm of social space" (1991, p. 15), or social conception of space, created by the everyday use of space. He further argues that this separation, while theoretical, has political implications because it "creates an abyss between the mental sphere on one side and the physical and social spheres on the other" (1991, p. 6). In other words, Lefebvre is arguing that there is a fundamental difference in the way space is thought about or planned, and the way it is actually used and experienced. This focus on the relationship between the "concept" and the "reality", or lived experience, of a space is crucial to understanding Lefebvre's main thesis that the mental abstractions used to plan space by contemporary policy makers and urban 
planners, and the process that makes these abstractions seem rational results in the repression of social differences, the classification of citizens as "users" and the appropriation of creative initiative in the production of space.

\subsubsection{The Social Construction of Space}

To support his theory on the production of space, Lefebvre develops a conceptual triad, consisting of spatial practice, representations of space, and representational spaces, which he refers to as "the perceived," the conceived," and the "lived" (1991, p. 33). Perceived space refers to the active practice of mastering and appropriating space through urban planning, architecture and urbanism (1991, p.25). It includes the surveying of land, zoning, the regulation of urban development, and the process of designing infrastructure for use. According to Lefebvre, urban planning necessarily abstracts space and spatial practice, in order to influence the production of space in a strategic and instrumental manner. In other words, space is captured within a technical sphere, where only experts with specified tools can intervene and participate ${ }^{45}$.

Conceived space is described as a "system of localization [that] assigns an exact spot to each activity" (Lefebvre, 1991, p.45) based on an understanding of its "perceived" spatial nature. In other words, planners utilize carefully crafted drawings, maps, ordinances, etc. to translate their perception of social space into a representation of space that promises to achieve a particular end. An example of this would be the creation of

\footnotetext{
${ }^{45}$ It is important to note that the Production of Space was originally published in French in 1974, and thus the urban spaces and planning practices alluded to and referenced within the text should be understood within this context. However, within this work I have attempted to demonstrate the continued relevance of Lefebvre's critique of social practice.
} 
revitalization plans to turn a rundown building or quarter into a strip mall, in order to increase economic activity and city revenue by attracting retail chains. These plans ignore and render absent the experiences of local businesses whose livelihoods will be compromised by these new retail chains. This process of designing space to accommodate or achieve particular ends requires that space be thought of as a material product, devoid of social relationships and history.

Representational spaces or lived spaces are "redolent with imaginary and symbolic elements, they have their source in history - in the history of a people as well as in the history of each individual belonging to that people" (Lefebvre, 1991, p.41). In other words, lived space refers to the images and symbols, often non-verbal, that people (either as a collective or individually) associate with certain locations or landmarks. These symbolic and emotive elements are normally held to be private and thus they are rarely incorporated into the planning and policy process.

Furthermore, for Lefebvre, the use of language is a key component of the way representational space develops. Lefebvre argues that the way a place is described influences the way it is conceived, which limits the scope of possibilities for intervention by making certain ideas and uses of space inconceivable.

A person's home is a clear example of the manner in which this conceptual triad operates. As a perceived space is it located in a clearly defined neighborhood, with a specified address, on land that is zoned for residential development and has achieved all the appropriate technical permits. As a conceived space, the house conforms to the city building codes and is built according to developer or neighbourhood enforced design standards. As a lived space it has both collective and individual representations. 
Collectively it is a symbol of adulthood, a signal of success in society and it acts as a means to recognize a family unit (as in those are the Gulamhusein's or that's the Gulamhusein residence). Individually, your home is a place for family and friends. It is a place that evokes warmth and safety, feelings of ownership and belonging. In some cases, it can also be a place of conflict. In either circumstance, it is an environment that changes over time in response to who lives there, what their relationships are, and even what month, week, day or time of day it is.

Lefebvre differentiates between the conceptual triad, i.e. the perceived, conceived and lived space described above, and argues that these concepts occur simultaneously and interact to produce social space, and thus cannot be understood as a model or a system. However, the conceptual triad does enable the recognition of mutually productive relations among the social and spatial at the individual and collective level. This permits us to consider a relationship between everyday urban life and the social forces that influence and power the production of space. In other words, the purpose of this conceptual triad is not to declare that urban planning is always detrimental or that policy makers and urban planners should not seek to regulate and plan urban space, rather the conceptual triad serves to articulate the societal power relations between the production of space and the experience of space in order to persuade readers that "[the] production process and [the] product present themselves [must be seen] as two inseparable aspects, not as two inseparable ideas" (Lefebvre, 1991, p.37). In this way, Lefebvre argues that space is both a product and a process of continuous production; and thus, for Lefebvre, the production of urban space must involve the reproduction of the social relations that are contained within it. Therefore, the production of urban space consists of far more than 
just the material space of the city; it involves producing and reproducing all aspects of urban life.

\subsubsection{The Implications of Abstracting Space}

At the same time, Lefebvre's distinction between perceived, conceived and lived spaces reveals the manner in which abstract space is produced, and highlights the implications of this form of abstraction. In particular, he identifies two "illusions", transparency and realism, that repress social difference, disenfranchise urban inhabitants, and result in the appropriation of creative initiative. Transparency refers to the notion that space is a material object that can be fully understood and captured within the mental activity of experts. Professional representations of space are developed and implemented based on knowledge derived from site plans, GIS mapping, texts and drawings (including computer generated drawings) and seemingly vacant, un-inhabited, or abandoned places are transformed or improved through the implementation of function based structures intended to benefit a neighbourhood and its residents. This notion of transparency ignores the importance of place attachment, community history and other latent interests and develops homogeneous representations of space that can be easily utilized. In this way, as Lefebvre explains space is abstracted and removed from the reality of social practice.

The second illusion, realism, abstracts space from the social relations that produce and exist within it, by presenting the current organization of space as natural, rather than being subjectively perceived and socially produced. This presentation of the urban environment as a natural phenomenon disenfranchises citizens because it presents space as an object that cannot be changed, thus restricting what people conceive of as an 
appropriate use of the space. This process makes policies like zoning and subsidies for single family houses seem natural, thus concealing the manner in which urban governance occurs and the influence that social and political movements have on the decisions that shape city life.

Furthermore, these two illusions serve to obscure the influence space has on the way people behave. As Lefebvre explains,

Space lays down the law because it implies a certain order - and hence also a certain disorder (just as what may be seen defines what is obscene). ...Space commands bodies, prescribing or proscribing gestures, routes and distances to be covered (1991, p. 143).

In other words, the process of urban planning is not neutral. It has an influence on social and spatial practices and creates a system that rewards those who conform to the planned logic of the space. Consider for example the development of shopping malls or other privatized public spaces such as Street Markets that are advertised as "available to the public". These spaces, Lefebvre argues are actually only available to a specific group, shoppers, and in some cases particular shoppers (those with considerable disposable income). In many cases these locations are only accessible if you follow certain procedures that are determined by the professional representation of the space. For example, homeless individuals or other individuals that appear marginal may be prohibited from "hanging out" in malls or markets. At the same, mainstream women with young children are provided with specially arranged places to feed, change and entertain their children. It is the unquestioned acceptance of these procedures as natural and logical that Lefebvre considers the dangerous aspect of abstract space. As he explains, abstract spaces "confuse matters precisely because they offer an already clarified picture" (1991, p.189) that tells people that they only matter as users, that their imagination and creativity 
is inferior to that of professionals, and that their emotive experience with space is irrelevant. In this way, abstract space creates a system that represses difference and discourages creative expression and action.

\subsubsection{The Right to the City}

The identification of the implications of abstract space results in Lefebvre's call to action, conceptualized as the right to the city. In Lefebvre's conceptualization, the right to the city consists of two distinct aspects, the right of appropriation and the right to participation. These rights combine to produce a radical vision of social and spatial relations in urban areas.

Firstly, the right of appropriation does not simply include the right of urban residents to physically use, access, or occupy city space; rather, it includes the right for individuals to produce urban spaces that meet their needs and enables their "full and complete usage" of urban space in the course of everyday life (Lefebvre, 1996, p. 179). This right to appropriation challenges ideals of private property that are central to the functioning of a capitalist economy. At the same time, the prioritization of the usage interests of urban inhabitants over capitalist interests challenges the hegemony of the market economy and capitalist class relations.

Secondly, for Lefebvre, the right to the city entails the right for city dwellers to be centrally involved in the decision making and governance structures that produce urban space. This right of participation will enable the development of heterogeneous urban geographies influenced by the complex political identities and variable needs of urban inhabitants. However, it is important to note that according to Lefebvre, the right to the 
city necessarily involves the production of urban space. Thus, urban residents, as contributors to the urban lived experience and the development of lived space, are the only individuals able to legitimately claim the right to the city. In other words, citizenship and enfranchisement is determined by inhabitance in the city. All urban residents, regardless of nationality, have the same right to decision making and participation in the production of city space and are thus equally enfranchised. This form enfranchisement challenges conventional notions of citizenship and participation.

\subsection{Social Inclusion and Exclusion}

The purpose of this section is to review the social inclusion and exclusion literature and consider how this concept is defined and used in political and academic discourse. The phrase social exclusion was coined by French Social Action Secretary of State, Rene Lenoir, to refer to the experience of marginalized individuals such as those with "mental and physical disabilities, the suicidal, aged, abused children and youth dropouts, adult offenders, as well as substance abusers" (Ebersold, 1998). The term was initially used as a mechanism to consider how poverty acts as a barrier to effective or full participation in society, and thus leads to social disintegration (Atkinson, 2000; Barata, 2000; Du Toit, 2004).

By the early 1990s however, it was generally acknowledged that even though most socially excluded individuals were poor, income was not the only criterion for determining levels of social inclusion (Davies, 2005). Rather, individuals were also disconnected from mainstream society by their social position, and a variety of sociocultural, political and institutional factors such as poor health; an inability to engage 
actively in politics; limited access to services, including health care, education and basic utilities, which serve to restrict people's ability to maintain social networks, take part in community celebrations and activities, and exercise their freedom of expression and decision making power (Mitchell \& Shillington, 2002; Oxoby, 2009; Luxton, 2002). Additionally, scholars such as Freiler (2001) present inclusion as a normative concept that "requires more than the removal of barriers. It requires investments and action to bring about the conditions of inclusion" (p.2). This assertion is supported by Chisholm (2001) who emphasized the importance of “capacity and agency...of [people's] ability to play an active role in influencing their circumstances and making autonomous decisions" within the definition of social inclusion (p.32; see also Atkinson, 2000). Similarly, for Robinson (2000), social inclusion is "a situation where everyone is able to participate fully in society and no one is blocked from doing so by lack of political and civil rights, by lack of employment or income, by ill-health or lack of education" (p.154). Others argue that social inclusion is about "belonging, acceptance, and recognition" and thus the human qualities associated with inclusion are important (Freiler, 2001).

As the above discussion demonstrates, social inclusion is difficult to define as it is represents the interaction between a variety of factors. For this reason, several authors such as Burchardt, Le Grand, \& Piachaud (2002) have developed a conceptualization of social inclusion that includes four dimensions:

1. Consumption: the capacity to acquire necessary and desired goods and services;

2. Production: participation in economically or socially valuable activities, as defined by the individual;

3. Political engagement: involvement in local or national decision-making processes; and 
4. Social interaction: integration with family, friends and community.

This definition of social inclusion, as multi-dimensional concept, is valuable because it encompasses the economic, cultural, social, political, historical and institutional factors that enable individuals and groups to engage meaningfully in society, and thus broadens the scope of the concept considerably (see also Mitchell \& Shillington, 2002; Freiler 2001; Avramov, 2002).

\subsection{Relationship between Social Inclusion and the Right to the City}

Social inclusion has a clear spatial manifestation, because access to decision making power; resources; and meaningful social, economic and political participation are negotiated within specified social, political and cultural spaces. As Madanipour (1998) explains, there is a direct relationship between the spaces we can choose to inhabit and the level of social inclusion we experience. This is because public spaces provide the environments where people from various socio- economic, political and cultural backgrounds come together to engage in conversation, participate in common civic celebrations, access and share relevant information about socio-economic, political and cultural opportunities, and get involved in community life (Caidi \& Allard, 2005; Polese \& Stren, 2000; Donnelly \& Coakley, 2002).

In addition, Mitchell (2003) develops the work of Lefebvre (1991) and explains that there is a relationship between geography and social justice; public spaces are "socially produced through use, they arise out of conflict between representational and representation space" (p. 129). In other words, the social construction of a community results in an inherent tension over the use of public spaces; are public spaces "representative", intended as sites of inclusion, where "public movements can organize 
and expand into wider areas" or are they simply places "open for recreation and entertainment, subject to usage by an appropriate public” (Mitchell, 2003, p. 128).

This discussion over the appropriate or intended use of public space is important to consider because, as Lasch (1996) argues, the existence of public space is not a sufficient condition to promote social inclusion ${ }^{46}$. Rather, it is important to examine how these spaces are created and the manner in which access to these spaces is controlled. This argument is similar to the right of appropriation and participation articulated by Lefebvre (1991), who asserts that physical access is not a sufficient condition to achieve the right to the city. Rather, individuals must have the right to create spaces that meet their needs and must be empowered to engage in and influence the decision making regarding the use and control of these spaces.

Furthermore, as Polese \& Stren (2000) explain, civic institutions and informal meeting places are disappearing, as public space becomes increasingly subject to private control. In addition, in many cases bylaws, video surveillance and the use of private security serve to control public spaces by regulating who can access the space and under what conditions (Doherty et al., 2008). This trend towards the regulation and privatization of public space limits the ability of marginalized populations to access public resources, engage in civic activities, and share information; and thus has an impact on social inclusion. These developments support the assertion made by Lefebvre (1991), who argues that space is not neutral. Rather it seeks to create a system that rewards specific behaviour that conforms to the planned conceived logic of the space. In this way, the regulation of space serves to limit the creativity and action of urban residents. It also

\footnotetext{
${ }^{46}$ As referenced in Polese \& Stren (2000)
} 
disenfranchises urban citizens by classifying them as users only and eliminating their influence on the mechanisms that create, control and manage space.

This discussion of the difference between conceived, perceived and lived space, as well as the consideration of the implications of abstract space on social inclusion and the right to the city provide a theoretical basis for analyzing the experience of Aboriginal peoples in the City of Edmonton. The next chapter will use the differing identifications of space (perceived, conceived and lived) identified within this chapter to compare and contrast the definitions of public space provided by Community Service Organizations, City Officials and other managers or regulators of public space, and Aboriginal residents; and consider whether these differing conceptualizations of space impact the ability of Aboriginal people in Edmonton to experience inclusion and obtain the right to the city.

\section{Chapter: Perspectives on Aboriginal Inclusion and Access to Public}

\section{Space}

In order to consider the manner in which public space is conceived and understand the role or influence of Aboriginal people in the creation, management and regulation of space ${ }^{47}$ in the Boyle Street, McCauley and Downtown neighbourhoods of the City of Edmonton, a number of representatives from key Community Service

\footnotetext{
${ }^{47}$ All the public spaces identified within this study were identified through the application of the definition of public space identified in Chapter 2 and in consultation with a representative of the City of Edmonton. Additionally, all focus group participants were asked to verify the list and identify any spaces that may have been missed. All Community Service Organization representatives, City Officials, and other representatives selected to participate in interviews for this study were/are actively involved in the creation and day to day management and operation of at least one of the identified spaces. For a list of all identified spaces, see Appendix D
} 
Organizations were interviewed. In addition, focus groups were conducted with Aboriginal people residing in these communities to determine how these individuals perceive public space, determine their level of accessibility with regards to public space, and provide individuals with the opportunity to speak to their experience of social inclusion or exclusion in the community as it relates to the accessibility of public space. This chapter provides a discussion of the key findings that emerged from these interviews and focus group sessions.

The chapter will consist of two sections. Section one will provide a discussion of the four key questions considered by representatives and focus group participants, i.e. how is public space defined, who constitutes the public, what role do Aboriginal people have in the decision making process of creating, operating and regulating public space, and does accessibility to public space broadly defined impact the level of social inclusion experienced by Aboriginal people. In this section, perspectives from representatives and participants will be presented side by side to identify points of commonality and difference. Material from the review of key documents (identified in Appendix A) will be used to provide clarification or supplementary information to support the perspectives offered by participants and representatives.

Section two will identify the main themes that emerged from the narratives presented by focus group participants with regards to the accessibility of public space. This section is intended to highlight the challenges faced by Aboriginal people as they access and appropriate urban space in Edmonton in a manner that enables the expression of their identity and culture; and draw attention to the contributions of Aboriginal peoples 
and communities to the renewal and sustainability of urban spaces in the City of

Edmonton.

\subsection{Space Place and Regulation}

\subsubsection{Defining Public Space}

Even though a stipulative definition of 'public space' for the purposes of this study was provided to participants, the way public space is defined generated a great deal of discussion. Amongst key informants and representatives of Community Service Organizations, there were two primary issues: ownership and functionality.

\subsubsection{Ownership}

The definition of public space provided to participants clearly indicated that, within this study, the term public space refers to usage or perceived usage of space, rather than actual ownership. Despite this, representatives ${ }^{48}$ clearly differentiated between publicly funded space that was open to the public, and privately owned space that is intended for public usage. As one representative explained:

listen, you have to separate the two. You can't look at publicly funded space and privately owned places as one and the same. My organization owns this space. The city owns the park. (Representative from a Community Service Organization (Boyle Street), Feb. 12, 2014).

This concern over ownership within the definition of public space is important because of the ten Community Service Organizations interviewed; six did not consider the spaces

\footnotetext{
${ }^{48}$ To distinguish between focus group participants and representatives of organizations that either create, manage, or regulate public space; the following terminology will be used: focus group participants will be referred to as participants; and representatives of organizations will be identified as representatives.
} 
they create and operate to be public space. In fact, representatives from these organizations adamantly opposed the representation of spaces within their organizations as public space. For example:

we are not providers of public space. Sure we run a drop-in centre as part of the services we provide, but that's not the same as public space (Representative from a Community Service Organization (Boyle Street), Feb. 12, 2014).

We are a non-profit organization and we own this building. Technically that means we are a 'private' institution (Representative from a Community Service Organization (Boyle Street), Feb. 18, 2014).

Just because we work in the community and are open to the community does not make us public. I wouldn't say we are a public place (Representative from a Community Service Organization (McCauley), Feb. 20, 2014).

In my mind, public space is anything that is not privately owned. For example, the space in between the two buildings you just saw that's public space. It is owned and managed by the city (Representative from a Community Service Organization (Boyle Street), April 8, 2014).

This identification of ownership as the key determinant of whether or not a space is considered public space was also echoed by officials from the City of Edmonton Parks and Recreation Department, representatives from the Boyle Street and McCauley Community Leagues ${ }^{49}$, and representatives from the Boyle Street Renaissance Association and the McCauley Revitalization Association ${ }^{50}$. As one of the City of Edmonton Parks and Recreation Department officials explained:

\footnotetext{
${ }^{49}$ The focus on ownership from Community League representatives was particularly interesting because Community Leagues are located on City owned land (see Boyle Street Renaissance Report II in Appendix A)

${ }^{50}$ This emphasis on ownership was not evident in the discussion with the representative of the Edmonton Public Library
} 
Parks, rec. centres, playgrounds, etc. are public space only if they belong to the city. You have to be careful about how you define public space. There are a lot of so called public spaces that are actually privately owned, so you can't really put them in the same box and call them public (City of Edmonton Parks and Recreation Department (Boyle Street), Feb. 26, 2014).

This focus on public ownership as the key criterion for the classification of space as public space is in direct contrast to Aboriginal community perspectives on the definition of public space, which will be discussed below.

\subsubsection{Functionality of Space}

Furthermore, with the exception of one Community Service Organization and the Edmonton Public Library, every representative identified and distinguished between spaces based on the intended purpose of the space, i.e. whether it was a service space, recreation/leisure space, or a commercial space. Of the ten organizations interviewed, seven considered themselves to be service oriented. In other words, they are spaces created specifically for the provision of particular services to a specified community or client base. For example:

We are essentially a service provider. We provide counselling services, housing placement services, employment services and so forth (Representative from a Community Service Organization (Boyle Street), March 3, 2014).

Our mission is to serve the community. We provide homeless men, women and children with basic and emergency care (Representative from a Community Service Organization (McCauley), Feb, 20, 2014).

We function like an information house. People come to us to access a variety of services- some, like Housing services we provide in house; others we do referrals for (Representative from a Community Service Organization (Boyle Street), Feb 12, 2014). 
We provide faith based services to the community (Representative from a Community Service Organization (Boyle Street), April 8, 2014).

In addition, two of the representatives interviewed identified the organizations or city properties they represent ${ }^{51}$, as providers or managers of recreation or leisure spaces. In other words, they identify the spaces they operate, manage and regulate as spaces designed for particular/specified types of leisure and recreational activities ${ }^{52}$. For example:

I am responsible for the management of parks and recreation facilities in this community. Basically I am the person people call if they want to rent a picnic spot for a birthday celebration, or want to use the park for yoga lessons, or want to rent a room at the rec. centre. I facilitate these rentals; make sure the activities they are proposing are appropriate and that they have the permits they need (City of Edmonton Parks and Recreation Department (Boyle Street), Feb. 26, 2014).

Lastly, one representative identified the spaces he is responsible for as a commercial space, i.e. a space intended for the operation of business. As anticipated, this individual was not inclined to identify the space he represents as public space. He acknowledged that the spaces were accessible to the public, but clearly differentiated private commercial space from public space. As he explained:

This is my family's business. My wife and I run it. Just because people use our shop as a place to hang out doesn't make it a public place (Representative from a Community Business (Boyle Street), April 8, 2014).

\footnotetext{
${ }^{51}$ In some cases the individuals interviewed represented or managed access to more than one public space. This was especially true in the case of the officials from the City of Edmonton Parks and Recreation Department.

${ }^{52}$ For a definition of what constitutes a recreational space see the City of Edmonton Recreation Facility Master Plan listed in Appendix A.
} 
In contrast to most of the representatives interviewed who did not perceive the spaces they manage to be public spaces, the representative of the Edmonton Public Library clearly articulated the belief that the library was one of the last public spaces left in the city. As she explained:

I think the library is almost the last remaining public space where people can come and spend time freely without any expectation that they are going to shop or have some kind of other motive for being there. There are not very many places where people can just be. And I would say that we certainly recognize that, as a library system we recognize that we have that role (Representative from the Edmonton Public Library, March 22, 2014).

One of the Community Service Organizations located in Boyle Street was also conceptualized differently by its representative. Even though the representative did not explicitly refer to the place as a public space, he defined it as a celebratory space; a space defined and created for the purpose of community building and celebration. As he explained:

We knew the community needed a place to also celebrate and gather, so it serves the purpose on one hand of people just coming here and resting at a table, participating in some events, accessing services. And then there is the other component which is if you will the celebratory events that we have, both of a spiritual nature and a community celebration nature (Representative from a Community Service Organization (Boyle Street), April 9, 2014).

As the discussion above demonstrates, majority of the representatives interviewed defined public space by ownership and intended purpose, or function, of the space. However, in most of cases, representatives' prioritized ownership over functionality, and thus, the primary criterion utilized to define public space was whether a space was owned by the city. Spaces owned by non-profit organizations or private entities were not 
considered public spaces, even though they provided free services to the public, and received public funding to offer these services ${ }^{53}$.

In contrast, community members appeared to reverse the order. Functionality (uses and users) was the primary criterion used by focus group participants to define any space as public or private. Examples of descriptions by focus group participants are recounted below:

Public space is like the library. You can be comfortable there. You can relax, sit in a corner and read and forget that it's cold. That you are sad. That things are not - the best sometimes. No one cares how scruffy you look. Other places they don't give you that. You go in and they want to ask you all kinds of questions. It's not about relaxing and being yourself it's about them and their stuff. They don't offer you a chance a time to be at peace, to just be. They don't offer anything that makes you want to go (Chloie ${ }^{54}$, age 47$)$.

...public space is more than just a place where you can hang. It's a place where people like us can be private. You know you can have your own little place (Doreen, age 45).

Public space is where the public can come together. Like a public parking area, a drop in centre, the mall, community meeting, band meeting. It's where all my friends are. It's the kind of the places we hang out, we go window shopping and well just whatever you know. It's wherever there is no boundaries (Lane, age 33).

Public space...it's like here. It's a place that's my place. We hang out here. We are safe here. We have control (Frank, age 52).

It's a place to chill, to smoke weed without being bothered, to be able to walk down the street, do whatever whenever (Jesse, age 18).

\footnotetext{
${ }^{53}$ All but one organization interviewed within this work received public funding from a variety of government departments including, Alberta Housing and Urban Affairs, The City of Edmonton, Alberta Health Services, Health Canada, the Public Health Agency of Canada, Alberta Justice, and Aboriginal and Northern Affairs Canada (see Appendix A for a list of Community Service Organization web pages/annual reports).

${ }^{54}$ All participant names used within this thesis are pseudonyms selected by the participants. This is in accordance with best practices identified by Graveline (2000) in her article, Circle as methodology: enacting an Aboriginal paradigm.
} 
Public place is where you go to have contact with someone else (Michael, age 25).

This articulation of space according to usage or the everyday lived experience of the space is more consistent with the definition of public space articulated within the research design of this study and the definition of "representational space" offered by Lefebvre (1991). The classification of space according to function and ownership is also consistent with components of Lefebvre's conceptual triad ${ }^{55}$, specifically "the perceived" and "the conceived" nature of space $(1991,33)$. This difference between the definition offered by representatives and the one posed by participants is significant because it highlights the tension over the conceived nature of space versus the representational nature of public space that Lefebvre (1991) identifies.

According to Lefebvre (1991), the characterization of space according to its material reality- i.e. its ownership (perceived nature) and function (conceived nature) results in the abstraction of space, which serves to limit the way urban inhabitants imagine, create and utilize space (representational nature). As Lefebvre (1991) asserts by abstracting space, people are offered "an already clarified picture" $(1991,189)$ of what is acceptable, appropriate and possible within the space. In other words, the conceived nature of the space, i.e. its intended purpose as a service, commercial or recreation/leisure space works to control the type of activity individuals may engage in within the space. A person may not, for example, expect to obtain a service within a leisure space or expect to be at leisure within a service or commercial space. ${ }^{56}$ In this case, representatives

\footnotetext{
${ }^{55}$ See chapter 3 page 39

${ }^{56}$ Interestingly, a key principle identified in The City of Edmonton Recreation Facility Master Plan (listed in Appendix A) is to "combin[e] recreation, library, arts, heritage and health services...and some social services such as youth employment centres, well-baby clinics, nutrition classes, etc... within the City's
} 
clearly saw the spaces they represent according to their material reality, i.e. the conceived nature or intended purpose as a service, recreation or commercial space. This conceived nature directly influenced the type of activities they deemed acceptable. For example:

We have a family programming centre that people can access, but it's not for everyone. It's for people who are partaking in the programming that is going on (Representative from a Community Service Organization (McCauley), Feb, 18, 2014).

Our space is small and we are here to provide services. People come in, they get what they need and then they move on. We don't encourage people to hang about and loiter (Representative from a Community Service Organization (Boyle Street), Feb.18 , 2014).

When managing parks we are faced with multiple interests. There's the business owners in the area who want the place to be friendly for customers, there's the homeowners and other community members who want the park to be a place where they can take their kids and there is the homeless community. So we need to balance these multiple uses and regulate the kinds of activities we allow. We do this by designating areas/facilities for specific purposes through signs and the Parkland Bylaw ${ }^{57}$ (City of Edmonton Parks and Recreation Department (Boyle Street), Feb. 26, 2014).

Every organization has a policy that regulates behaviour. Outlines what you can and cannot do. In our case we are clear. Offices in the building are intended for administration, clients are not permitted. Client service or program areas are for service provision; registered clients are allowed while programming is happening (Representative from a Community Service Organization (Boyle Street), Feb. 18, 2014).

This restriction on the manner and type of activity individuals may engage in within public spaces, as demonstrated by the above statement, and the classification of space

recreation facilities" (p.52). This demonstrates that the City is aware of the need to create integrated facilities and the impact this has on inclusion, however simply planning to have spaces within these facilities has not necessarily resulted in the actual creation and management of inclusive integrated multiuse environments in the Downtown, Boyle Street or McCauley communities.

${ }^{57}$ The Parkland Bylaw 2202 provides guidance on permitted activities in city parks and recreation areas including trails. The Bylaw also provides power to peace officers to enforce bylaw provisions through the removal of persons from spaces and the imposition of fines. To access a copy of the Bylaw see: http://www.edmonton.ca/bylaws_licences/C2202.pdf 
according to function and ownership have implications on the way representatives

defined the "public". This will be discussed further below. Furthermore, the conceptualization of public space as referring exclusively to spaces that are owned by the public, not spaces used by the public influences the manner in which representatives manage and regulate the spaces they are responsible for, and the way participants' experience social inclusion. This will be discussed further in this chapter

\subsubsection{Who's the Public?}

The definition of space according to function and ownership has a direct implication on the manner in which organizations defined the "public". For the most part, representatives were concerned that including drop-in facilities, communal areas in Service Organizations, the Public Library, the food court in the mall and the waiting area at the bus and LRT stations within the same consideration of public space as Winston Churchill Square, or City owned recreation facilities would result in confusion over who the intended audience of a space is. As one representative explained:

I understand that you are interviewing a bunch of community organizations as well as people from the city. But you have to remember...our mandates are completely different, who we serve is different (Representative from a Community Service Organization (Boyle Street), Feb. 18, 2014).

Two key themes emerged from this discussion of who constitutes the public. These themes will be discussed below. 


\subsubsection{Labeling the Public: Client, Customer, or Community Member}

Individuals that use or access the spaces being considered within this study were identified by representatives according to four labels, client or user; customer; community member; or neighbour ${ }^{58}$. Six Community Service Organizations chose to utilize the client-user label to define the individuals they engage with. Examples of how the client or user label was articulated by representatives include:

... our aim is to provide service to our clients in manner that is respectful (Representative from a Community Service Organization (McCauley), Feb, 20, 2014).

Our services are targeted to the specific needs of our clients in the neighbourhood (Representative from a Community Service Organization (Boyle Street), March 3, 2014).

In addition, one representative utilized the customer label to identify individuals that engage with the spaces they represent and three Community Service Organizations referred to the individuals they engage with as community members or neighbours. The community member and neighbour labels were also utilized by city officials, the officer from the Edmonton Police Service and the representative of the Edmonton Public Library. Examples of the use of community member or neighbour include:

We don't call them clients here. They are community members and neighbours and we use those terms quite deliberately (Representative from a Community Service Organization (Boyle Street), April 9, 2014).

We work with the community, to ensure that every member of the community feels safe and secure in the neighbourhood they live in. That is essentially our job. We encourage our street workers to get to

\footnotetext{
${ }^{58}$ The term stakeholder appears in all City of Edmonton planning documentation reviewed (as listed in Appendix A). The term citizen also appears in one document (City of Edmonton Public Involvement Handbook) listed in Appendix A. However, neither of these terms is used by any participant or representative.
} 
know community members and build relationships (Representative from a Community Service Organization (Boyle Street), April 8, 2014).

We strive to be a good neighbour to the people who live in this community (Representative from the Edmonton Police Service, May $5,2014)$.

As the discussion above demonstrates, majority of the representatives interviewed labeled the individuals that access the spaces being represented as clients, users or customers. In contrast, most focus group participants identified themselves as community members or Edmontonians ${ }^{59}$ :

My mom moved here from the reserve and then she had me. So I have lived here all my life. I was born at the Grey Nuns. How much more Edmontonian can I get? (Michael, age 25).

Sometimes you just want to scream and say Hey! I live here too you know. This is my community too (RJ, age 17).

...they look at us like we are rats on the street, like we don't belong. We are part of the community too (Chloie, age 47).

This difference in the identification of the public is relevant because it supports a key component of the argument being advanced by Lefebvre (1991), who claims that the abstraction of space results in the classification of citizens as "users", and the appropriation of creative initiative in the production of space. In other words, Lefebvre (1991) is arguing that by abstracting space (i.e. defining it according to its material reality- in this case ownership and function), individual experience with space (the

\footnotetext{
${ }^{59}$ It is important to note that none of the participants identified themselves as being members of the Aboriginal peoples that resided in this area since the early 1800s. None of the participants identified as members of the Papaschase Cree or the St. Albert Métis. Rather, most participants had migrated or were from families that had migrated from nearby First Nation Reserves and/or Métis Settlements. For this reason a comprehensive discussion of the implication of Edmonton's history of relocating reserves was not as relevant to participants.
} 
representational nature) is lost. This results in the classification of citizens (defined by

Lefebvre (1991) as urban inhabitants) as mere users of space, a phenomenon that represses difference and discourages creative expression and action. As users, people are told that their imagination and creativity is inferior to that of the professionals who designed the space according to its functionality, and that their emotive experience with space is irrelevant. This has implications for the manner in which individuals experience accessibility to public space and social inclusion. As several participants explain,

Nothing is really going to change here. Not for us at least. People don't really see us. I mean ...think about it, we are the ones that used the parking lot the arena is on. But no one asked us what we wanted. Instead they are spending fucking millions we don't have building a stupid mall in a community that doesn't have enough housing. They don't want to help us (Lane, age 33).

You know what makes me angry? People come talk to us all the fucking time, but no one is really listening to who we are and what we want. I mean all these fancy places coming up all over the place...who is going to use them? You think I can go in there all scruffy and buy some fancy thing? (Willow, age 38).

This used to be a place where people were okay with us. But things are changing. All these new places means new people are coming in and they are not as nice. Someone actually threw their cup at me yesterday and I wasn't even panning or anything. I was just sitting there (Doreen, age 45).

In this way, as Lefebvre (1991) explains abstract space creates a system that ignores place attachment, community history and other latent interests, thus rendering the experience of everyday city dwellers absent and removing space from the reality of social practice. Thus rather than sites of inclusion, public spaces become simply places "open for recreation and entertainment, subject to usage by an appropriate public" (Mitchell, 2003, p. 128). 


\subsubsection{Identity Blindness}

In addition to labeling individuals as a client, user or customer, every representative interviewed expressed discomfort with the request to speak to their organizations' relationship with the Aboriginal community specifically ${ }^{60}$. This is because the organizations being represented all identify themselves as operating in an identity blind environment $^{6162}$. In other words, every representative believed that the organization they represent provides equal access to service or space to all individuals without regard for the racial or ethnic identity of the individual. For example:

I am having a reaction to the ethnic labeling we are using in this discussion. We are inclusive of all the residents in the neighbourhood. Safety and security is big for all ethnicities so that's my challenge, we don't really differentiate (Representative from a Community Service Organization (Boyle Street), April 8, 2014).

We try to be mindful of people and make sure they are not displaced immediately. We are trying to initiate more respectful procedures with dealing with all individuals in the community. In this we don't really care who the people are or what ethnicity they are - we respect everyone (Representative from a Community Service Organization (Boyle Street), March 3, 2014).

\footnotetext{
${ }^{60}$ The desire to maintain identity blind service provision is particularly interesting because in all but two of the key documents (listed in Appendix A), there is explicit recognition of the growth of the Aboriginal community and of the unique demographic and/or socio-economic characteristic of the Aboriginal community.

${ }^{61}$ However, in the 2005 Report of the Task Force on Library Services for Aboriginal Peoples, the Edmonton Public Library recognized that even though Aboriginal people do use the Edmonton Public Library, its services and programs were not focused on meeting the expressed needs of Aboriginal people and acknowledging Aboriginal people and their cultures (see Appendix A for full report and recommendations).

${ }^{62}$ The City of Edmonton has also acknowledged the need to strengthen its relationship with urban Aboriginal people in the declaration by Edmonton City Council on August $30^{\text {th }}, 2005$, part of which states: "We understand that as a group, Aboriginal people do not experience the same level of well-being and quality of life as many other groups in our region. Aboriginal people experience significant disparity in the areas of education, health and justice and face inordinate levels of poverty, under-employment and other social problems including racism. These struggles have exacted painful outcomes for Aboriginal Peoples. The imbalances call for the active involvement of Aboriginal people in identifying the issues and priorities and in developing partnerships and well-supported plans of action to achieve needed change" (see Appendix A for document reference).
} 
It is hard for me to speak to Aboriginal usage specifically because we don't really collect that information. I mean anecdotally sure we know we have Aboriginal users, but it's hard to say how many and we don't treat them differently (Representative from a Community Service Organization (McCauley), Feb. 20, 2014).

This assertion of identity blindness and equality of access and service is in direct contrast to experiences recounted by Aboriginal participants, as demonstrated by the following examples:

...people judge you by who you are. They look at you from head to toe and then tell you to move along (Lewis, age 32).

I went to high school here in the neighbourhood. A bunch of guys would always go to the Macs at lunch, hang out...get some smokes and they'd always be like come along man. So this one time I thought...fuck it I'll go. Most embarrassing moment ever. The dude wouldn't let me in the store. And you know what the sad thing was...all them white kids...not a single one of them had any fucking money to buy anything. They fucking borrowed it from me! (Michael, age 25).

I don't go there [the mall]. The security people have an issue with us. With Natives, and in general with people like us (RJ, age 17).

Furthermore, identity blindness is also in opposition to the desire of Aboriginal community members to obtain culturally appropriate services; and identify with, practice and celebrate their cultural identities within the public spaces of the city. Additionally, as explained by participants, the identity blind nature of spaces and organizations within the community limits the level of social inclusion experienced by Aboriginal people, because their inclusion in a homogenous classification of client, user, and customer subjugates 
their cultural identity to a need based identity thus limiting their opportunity to effectively engage in the community ${ }^{63}$. For example:

Most of us here are mentally, physically and emotionally traumatized by something and we need people to understand that. But we are more than that. We need people to know our history, recognize that we are Indian, and that makes us different (Rain, age 36).

It's hard because...I want people to see me as Métis but not see me as Métis at the same time. That doesn't make sense right? I want to be part of the community but I don't want that to mean I have to give up being Métis. And sometimes that's how I feelthat I have to pick (Tyler, age 42).

....as long as the worker recognizes that I am a band member I am ok. My band identity is very important to me. I am reservist and I am proud of it (Frank, age 52).

People always see us as in need, as if we are just a number on a paper. It gets pretty tiring (Anne, age 44).

Even though the examples recounted within this study highlight negative

interactions between Aboriginal and non-Aboriginal community members, it is important to note that this research does not intend to homogenize the perspectives of nonAboriginal peoples or suggest that all non-Aboriginal peoples harbour racist and discriminatory views towards Aboriginal peoples. Rather, this section is intended to highlight the ambiguity present in the relationships Aboriginal people form with service providers and other non-Aboriginal community members.

\footnotetext{
${ }^{63}$ In every planning document listed in Appendix A, Aboriginal people are included in planning discussions as stakeholders alongside Community Leagues, business owners, various associations and community organizations, and other City residents. This inclusion of Aboriginal community members in planning discussion is important, however the classification of Aboriginal people as just another stakeholder is reflective of a form of identity blindness that ignores Aboriginal people's desire to integrate their culture and identity into the decision making process.
} 
Specifically this section is intended to draw attention to the inherent tension that results from the identity blindness expressed by Community Service Organizations, and the desire Aboriginal people have to recognize and celebrate their cultural identities as part of their urban identity. This tension and ambiguity in the relationship between how Aboriginal peoples see themselves and how the organizations, that manage, regulate and control access to public space, see Aboriginal peoples has implications for the degree of decision making authority afforded to Aboriginal peoples, as discussed below.

Moreover, as the examples above demonstrate, the manner in which Aboriginal people are perceived has an impact on their ability to engage in consumption, participate in socially and economically valuable activities and maintain positive social interactions with friends, family and the community, all of which are key indicators of social inclusion as identified by Burchardt, Le Grand, \& Piachaud (2002).

\subsubsection{Decision making process and authority}

Of the organizations interviewed, four Community Service Organizations, the Edmonton Police Service and the Edmonton Public Library indicated that they regularly include Aboriginal people within their decision making processes on a variety of issues including, program delivery, cultural events, and the aesthetic nature of spaces. Interestingly, all but one of these organizations identified the public as community members and neighbours. As explained by representatives:

One of the things we tried to do was create a good neighbour agreement one that says how are we all connected, committed and all responsible, regardless of who we are for the safety and security and well being of our community. These discussions led to the creation of this body like a neighbourhood vetting group to look at what's working and what isn't and think about how we can all be 
responsible for keeping our neighbourhood in a state that we all agree is healthy and vital and contributes to the renewal of this area. And we are inclusive. These discussion included organizations from across the community, including Aboriginal ones (Representative from a Community Service Organization (Boyle Street), April 8, 2014).

About five years ago there was an Aboriginal community librarian, whose job it was to reach out to the Aboriginal community. She was located at Milner, but it quickly became apparent that there are Aboriginal communities throughout the city so having one community librarian responsible for all of those groups throughout the city was not very efficient. So having community librarians throughout the system engage and deal with the communities, including the Aboriginal communities in their areas seems to work better. There is also the Aboriginal Services Team that focuses particularly on the week in June and the activities around that but certainly engage with the community on other events as they come up (Representative from the Edmonton Public Library, March 22, 2014).

We do community consultations through a number of ways. First there are the community liaison officers in each neighbourhood that engage with the community on a regular basis. Then we have the Aboriginal Community Liaison Council consisting of key Aboriginal people which meets every month to provide advice and dialogue. We also have the Community Advisory Council, on which one seat is dedicated to an Aboriginal representative. This council provides advice to the Chief of Police (Representative of the Edmonton Police Service, May 5, 2014).

We are a trauma sensitive organization, which means that we recognize the importance of continuously engaging people who have suffered traumatic experiences in decision making about how we operate and we have put in place structures to do that. Let me give you a concrete example, one of the things we were concerned about is line-ups. Many of our community members have memories of lining up for food in residential school or in prison and we wanted to be sensitive to that. So when we were designing the drop-in and thinking about how to place the kitchen and everything else we talked to people in the community. And what we heard was basically...don't be dumb. Standing in line is something everybody does (Representative from a Community Service Organization (Boyle Street), April 9, 2014). 
Additionally, a number of organizations (four) provided examples of engagement with the Aboriginal community on an ad-hoc basis ${ }^{64}$. In each of these cases, Aboriginal people were consulted on programmatic changes, i.e. changes to programs being offered within the spaces identified. For example:

We have an Aboriginal program coordinator. Her job is to design programs for the Aboriginal community, which often involves doing engagement sessions to figure out what clients need (Representative from a Community Service Organization (McCauley), Feb. 20, 2014).

We actually just completed a series of consultations with our clients, and a number of Aboriginal people participated (Representative from a Community Service Organization (Boyle Street), March 3, 2014).

We are committed to meeting the needs of the people that use our services. This means that we have to think about how well we are doing and update our policies and programs when things change. This process of evaluation always involves talking to people, including Aboriginal people. Getting their feedback on how things are going, what can be improved, etc (Representative from a Community Service Organization (McCauley), Feb. 18, 2014).

In each of these cases, the organization was one that identified the public as clients, users or customers. Furthermore, in two of these cases, consultations with Aboriginal peoples occurred as part of larger consultations with the organizations clients in general.

\footnotetext{
${ }^{64}$ A further example of engagement can be found in the Boyle Street Renaissance Report II (listed in Appendix A), which describes their process for engaging Aboriginal residents in the BRAC project. As described in the report: "BRAC recognized that among those to be served by the Boyle Renaissance initiative will be many Edmontonians from the city's Aboriginal population" (p. 12). As such, the public consultation process for the Boyle Renaissance initiative involved the Wichihitowin Circle of Shared Responsibility and the Aboriginal Community Action Circles that were developed as part of the Edmonton Urban Aboriginal Dialogue process, the Canadian Native Friendship Centre Board of Trustees, the Metis Urban Housing Program, and the Assembly of Tribal Chiefs of Alberta.
} 
In addition, representatives of every space identified within this study indicated that the organizations they represent make use of barring policies ${ }^{65}$ or a city bylaw for regulating access to space. However, only one representative indicated that Aboriginal people and other community members were regularly included in discussions on updates to the barring policy.

Furthermore, two of the organizations that considered Aboriginal people to be community members and the Edmonton Public Library also worked to include Aboriginal people and perspectives in the planning process for designing spaces ${ }^{66}$. As the representatives explained:

We also have an Aboriginal collection specifically that is not only a collection but a physical space that was actually designed in partnership with the community and blessed by an elder with a pipe ceremony (Representative from the Edmonton Public Library, March 22,2014).

In the [Planning Committee], there were a number of Aboriginal organizations and people that were part of that whole discussion. And part of the BRAP committee was to look at design principles and operational principles for the [project]. An example is the Artists quarters project, which is still in the planning stage. We have had some transitional art projects that has had Aboriginal artists and then as part of our permanent art for 96 street there will be Aboriginal artists included in that project (Representative from a Community Service Organization (Boyle Street), April 8, 2014).

Designing the space...well it was a little hard. We needed a bigger place and this was the only building available in the community so

\footnotetext{
${ }^{65}$ A barring policy is a policy that provides guidance on measures that can be used to enforce appropriate usage and behaviour within a space. The policy typically identifies a code of behaviour which lists unacceptable behaviours, a process for notifying individuals of violations to the code of behaviour and a process to bar the individual from accessing the space for a period of time subject to appeal (description based on review of Boyle Street Community Services Barring Policy listed in Appendix A).

${ }^{66}$ In addition, Aboriginal peoples were included in the City of Edmonton planning process as outlined in The City of Edmonton Recreation Facility Master Plan, the 10 Year Arena Capital Development Strategy, the Urban Parks Management Plan, and The Way We Grow Municipal Development Plan (as listed in Appendix A)
} 
we took it. But then we had to work with what we had. We tried... in the large drop in to engage with the community and create a kind of community village - a central common area surrounded by offices that are always open and accessible. Frankly, it sounds better than it looks. But we also worked with the community to paint the place, pick the art work and all that kind of stuff. I mean look around, everything on the walls is done by someone in the community (Representative from a Community Service Organization (Boyle Street), April 9, 2014).

The difference in level of engagement with Aboriginal peoples amongst the organizations interviewed and the concurrence with the way these organizations labeled the individuals they engage with suggests that the manner in which representatives defined who constitutes the public has an impact on the level of involvement in decision making afforded to Aboriginal people in the community. Organizations that considered Aboriginal people to be neighbours of community members were more likely to create mechanisms that facilitated engagement with the community over the long term. These organizations were also more likely to include Aboriginal people in discussions on a wider variety of space related concerns including design, management and regulation.

The narratives offered by focus group participants also support the idea that there is a relationship between how Aboriginal people are perceived and their level of engagement in decision making. For example:

...they go about it the wrong way... we'll take your opinion but we won't use it. They say well because you live on the street. Well there you go we are back to square one again. That's what we are trying to do. We are not trying to say do it or not but it makes a difference in a lot of things (Doreen, age 45).

These examples support the theoretical assertions of Lefebvre (1991) who claims that classification of urban citizens as users contributes to their disenfranchisement by eliminating their influence on the mechanisms that create, control and manage space. 
Furthermore, according to participants, their level of social inclusion in the community is influenced by the degree to which they feel empowered to make decisions in the spaces they engage with. As participants explain,

...the places I like the most are ones where I feel like I belong. Where people know who I am, where I can help out and actually change things a little (Michael, age 25).

I work security for festivals in the city. All my sons do too. The Fringe... it's my favourite. I do this because I like to give back. Feel like I have some say, some control in what happens in the places I like to go. This is important (Frank, age 52).

This notion that decision making power is a key component of social inclusion is supported by the right to participation articulated by Lefebvre (1991) and Mitchell (2003), who assert that through the right to the city, urban inhabitants, regardless of nationality, socio-economic circumstance, ethnic identity, political ideals or cultural backgrounds have the right to be centrally involved in the decision making and governance structures that produce urban space. For Aboriginal people this means being seen as active and contributing members of the community, and being able to exert some control over not only the programs offered in their community but also the creation, design and management of space.

\subsection{Appropriating Public Space: Stories of Inclusion and Exclusion}

This section of the chapter focuses on the right of appropriation, described as the right of urban inhabitants to produce urban spaces that meet their needs and enables their "full and complete usage" of urban space in the course of everyday life (Lefebvre, 1996, p. 179). In particular, this section will consider the responses of focus group participants, specifically the manner in which they describe their ability to use and produce spaces to 
support their cultural identities as Aboriginal people. This section will be divided into two parts. The first will consider the barriers to inclusion identified by participants; the second will outline mechanisms being used by Aboriginal people to create spaces of inclusion and belonging within the city.

\subsubsection{Barriers to Access and Inclusion}

Discrimination is the primary barrier to accessing public space identified by participants. The following paragraphs provide examples of discriminatory practices that Aboriginal peoples have experienced when accessing public spaces in the City of Edmonton.

Experiences engaging with police officers or other security services that regulate public space were not explicitly sought within the focus groups. However, ten participants provided narratives that highlighted their vulnerability to harassment from security services, transit officers, and police services. Examples from three participants are highlighted below:

The cops...they look at you from your feet all the way up. And then... they tell you to move along. Even if you are just sitting there. You comply... unless you feel like being an ass ...then you get arrested (Willow, age 38).

The cops are really mean to us. They will be belligerent and throw you in a drunk tank. They will say and do anything to hurt you and your well being, your mental health. They say stuff like...there is rich people here ...that live here. They don't need to see you. You are just a piece of shit living on people's money. They ridicule you. They make you feel like you are invading people's space (Chloie, age 47). 
Living in the city can be very difficult sometimes. You don't always get treated the way you should. People make assumptions about you based on what you look like. This one time, I was at the LRT station - going to see my kids, they live in Clareview- and the transit officer comes by, walks me to the stairs and says I gotta leave. Says he knows I don't have the fare so I should leave before he has to give me a ticket. I was pissed! He didn't even ask to see my ticket - which I had. He just assumed, because I'm Indian I must be trying to hop the train (Lewis, age 32).

In addition to harassment by security forces, participants also provided examples of negative experiences dealing with non-Aboriginal community members. Five participants describe instances of verbal abuse, being called things like "little ho", "drunken loser", "piece of shit" and "lazy". Three others provided examples of instances where they experienced physical abuse - one had a coffee cup thrown at her, one was assaulted, and one was raped. Narratives from two of the participants are recounted below:

I work at [the neighbourhood cafe] as a waitress. It often means walking home late by myself. This one night...I closed up and there were three guys having a smoke in the parking lot. At first I wasn't worried...I'd never had any trouble before. But that night...those guys followed me - they were whistling and yelling stuff at me. I got scaredstarted to run- but it was too late. One of them grabbed me...shoved me into a wall. I started to scream but he stuffed something in my mouth. I can still remember how it tasted - like old socks and sweat. I ...I am sorry... It's just ...I never expected it to happen... and I know it was probably only a few minutes...but it felt like hours. They took turns. Two of them...they held me down, and the other...I ...I'm sorry. Sorry...just give me a minute...When they were done, they tossed twenty bucks at me... they laughed and called me an 'Indian ho'... and then they just left! (Rain, age 36).

It happened a couple years back. I was hanging out by the casinosmoking some weed- and got jumped by these two guys. They were piss drunk and they beat the shit out of me - broke my fucking ribs. I got lucky...someone from Boyle Coop spotted them and called the cops That day...I remember thinking...this is it...I'm dead. My times up (Tyler, age 42). 
Additionally, three women described experiences where they were approached by people who believed they were prostitutes.

You got to be careful here. I don't go around by myself. There is always all these old guys trying to pick you up and stuff (Lois, age 18).

Furthermore, two participants also recount instances of stigmatization when accessing shopping or other commercial locations, such as convenience stores and coffee shops. As one of the participants describes,

There's this coffee shop by Giovanni Caboto Park. And this one day it was really cold so I thought I would go in and get something. I walked in and I hear the person behind the counter tell her co-worker in a very loud whisper, 'Watch that one. She'll probably steal something'. I just looked at her and walked out (Rain, age 36).

These experiences of discrimination and harassment have an impact on the level of inclusion experienced by Aboriginal people because they impact their ability to engage in consumption and social interaction, which are key indicators of social inclusion. They also have implications for the emotional wellbeing of Aboriginal residents of the city. Of the 14 participants in this study, eight recount moments where they have felt invisible, depressed, worthless, or otherwise stigmatized. The experiences of three participants are recounted below:

It was terrible. I was so scared! I thought people would laugh. But no one even noticed. It was like I wasn't even there (Lane, age 33).

Sometimes I get really depressed. I start to wonder if I made the right decision moving here from Slave Lake (Doreen, age 45).

Sometime there is just so much stigma and it is really hard for me. People put all these labels on you and you start to wonder where you fit (Lewis, age 32). 
As these stories demonstrate, Aboriginal people face significant barriers accessing public space in the city and to social inclusion. They are subject to discriminatory practices, preyed upon by other community members and often made to feel unsafe, unwelcome and unworthy. In this way, Aboriginal people are being denied the right to appropriate city space and remake it to suit their needs and desires, and thus by extension they are being denied the right to the city, as conceptualized by Lefebvre (1991).

\subsubsection{Mechanisms for Inclusion}

In addition to the experiences of exclusion described above, several participants also recounted instances where they were able to appropriate spaces, develop relationships or develop community norms that were more reflective of their personal identities and culture. In particular, seven participants highlighted the importance of the street family. Examples from two participants are provided below:

...the street family- you all know- they are like family. They are the key. It's who you trust. People you can rely on when you can't make it to shelter. They will throw you into a cart to make you safe (Chloie, age 47).

The people made me feel more welcome. The street people- we look out for each other here. It is a bit like having a weird ass family (Anne, age 44).

In addition to the importance of the street family, several participants highlighted the importance of community celebrations such as round dances, powwows and sweats. As three participants describe:

We hold a round dance in the community every year. It's amazing. The community organizes the whole thing. We run security, plan 
food, and bring the musicians and dancers. It's a time when we all work really hard to be clean and sober (Frank, age 52).

I love going to powwows. The ones organized by the Ben Calf Robe are my favourite (Willow, age 38).

Some of the organizations...they have an Elder come. Even though I am Cree and sometimes the Elder isn't... I still like to take my kids there. It's important for them to learn about our people. And often they will get invited to a sweat, which is great (Doreen, age $45)$.

As described by participants, these events provide Aboriginal people with opportunities to take control of space and participate in activities targeted to the expression of their identities and culture. These events, hosted by Aboriginal organizations or other Community Service Organizations and typically occurring in City Recreation facilities such as Commonwealth Stadium, in city owned and managed park spaces or on University of Alberta grounds (when sponsored by the Native Studies department), also provide the Aboriginal community with an avenue to engage the nonAboriginal community and raise awareness. As one participant explained:

"These events are great because they allow other people to come. We often get people from all over the community. They come and dance and eat with us and they realize we aren't so bad. They have a good time and then the next time they bring their friends and family and that's how it spreads" (Jesse, age 18).

The experiences of urban space recounted in this chapter highlight the challenges Aboriginal people face when accessing public space, including racism, assumptions of laziness or criminality, and continued association of Aboriginal identity with addictions, mental health concerns and other social problems. Participants highlighted their negative experiences interacting with security forces, recounted experiences of violence and vulnerability on the streets and instances of harassment and suspicion from store owners. 
These experiences made people feel uncomfortable and limited their ability to gain access to urban spaces, which impacted their social inclusion because it limited their ability to engage in consumption, production, social interaction, and political engagement.

In addition, there was an important difference in the way Aboriginal peoples understood public space and their role in relation to those spaces and how organizations or institutions understood those roles. As discussed in this chapter, Aboriginal people focused on usage and representational ideas of space when defining public space, while representatives focused on conceived and perceived ideas of space specifically on ownership and functionality. This difference is relevant because it highlights the abstraction of space and the disconnect between service providers, regulators and planners and actual urban residents, which is a key component of the conceptual argument presented by Lefebvre (1991).

Furthermore, whereas Aboriginal people considered themselves to be Edmontonians or community members, they were often labeled as clients or users by representatives. This labeling is significant because it restricted the ability of Aboriginal peoples to access decision making processes thus restricting their right to participation and appropriation of space and impacting their ability to engage socially and politically within their community, which has ramifications for social inclusion.

\section{Chapter: Conclusion and Recommendations}

This thesis explores whether the critique of spatial practice advanced by Lefebvre (1991) in his conceptualization of the right to the city can be combined with the concept of social inclusion articulated by Burchardt, Le Grand, \& Piachaud (2002), and applied to 
the study of Aboriginal peoples' experiences accessing public space in the City of Edmonton. In the preceding chapters, I have provided an overview of the argument presented by Lefebvre in his work The Production of Space and highlighted the manner in which common planning and policy making techniques and principles serve to abstract space, removing space from its social reality and defining it as a material product that can be easily manipulated.

While Lefebvre's critique of urban planning and policy making is not intended to suggest that planning is unnecessary or always negative, his ideas allow us to appreciate and recognize the extent to which planners and policy makers simplify, ignore, suppress, re-shape and restrict the social production of space, which results in the commodification of public space, the disempowerment of urban residents, the suppression of creative initiative and the prioritization of an understanding of social space in terms of its visible functionality, quantifiable character and systemic logic. This discussion also highlights the need for contemporary planning practice to consider the relationship between themselves and the people for whom they are planning.

In exploring the use of Lefebvre's theory of abstract and social space, this work has considered the way planners and regulators perceive their practice and the spaces they create, operate and control; and contrasted it with the perceptions of Aboriginal peoples, who's understanding of the urban environment involves their lived experience of being in a distinct social or "representational" space.

\subsection{Findings}


A number of key findings emerged from this investigation of access to public space, and the impact this has on social inclusion and Aboriginal peoples' right to the city. These findings are identified and discussed below:

\subsubsection{Differing definitions of public space}

Community Service Organizations, City officials and other creators, managers and regulators of public space differentiated amongst spaces according to ownership and functionality, rather than accessibility. In other words, they defined public space as places owned and operated by a public entity (i.e. the city) for a specific purpose (commercial, recreational or leisure, or service provision). This is in direct opposition to the definitions of public space offered by Aboriginal people, who focused on the representational nature of public space and described places according to their lived experiences of places as comfortable, safe, relaxing, enjoyable, etc. This difference in the definition of public space is important because it underscores the disconnect between the conceived reality of space as articulated by service providers and the lived or representational nature of space as experienced by Aboriginal people.

\subsubsection{Complex and Ambiguous Relationships}

The relationship between Aboriginal peoples, City Officials, and service providers is difficult to characterize because it occurs within a social context that is complex and results in an ambiguous definition of who constitutes the public. In this case, the need based identity-blind approach to defining the public utilized by Community Service Organizations comes into direct conflict with Aboriginal peoples' 
desire for cultural recognition, culturally appropriate service provision and rights based service delivery.

At the same time the classification of Aboriginal peoples as clients or users, rather than community members or neighbours de-legitimizes the place of Aboriginal people as contributing and valuable members of their communities. The client-user label limits Aboriginal people's participation and decision making authority by focusing their involvement in program delivery and evaluation specific discussions and is contrary to the community member, Edmontonian and neighbour labels used by Aboriginal peoples' to describe their place in the City of Edmonton.

\subsubsection{The Right to Participation}

Focus group participants identified the ability to exercise control and participate in the decision making processes for the design, management and regulation of public spaces as a key determinant of social inclusion. This is consistent with Lefebvre's assertion that the right to the city includes the right to participation, broadly defined as the right of all urban residents to be centrally involved in the decision making and governance structures that produce urban space. Even though many of the Community Service Organizations, the Edmonton Police Service and the Edmonton Public Library have mechanisms to engage with the Aboriginal community, these processes are largely ad-hoc and focused on the solicitation of input to facilitate program delivery and evaluation. 


\subsubsection{The Right of Appropriation}

Lefebvre (1991) identified the right of appropriation, defined as the right to use urban spaces in a way that supports the fulfillment of an individual's goals, aspirations and needs, as a key component of the right to the city. However, as focus group participants explained the ability of Aboriginal people to access public space is hampered by exclusionary practices that perceive all Aboriginal peoples as lazy, irresponsible, alcoholic, or engaged in criminal activity. Several participants expressed discomfort accessing public spaces and participating in civic celebrations, others recounted instances of verbal and physical abuse, provided examples of harassment by police officers and other security services, and described instances where they faced discriminatory attitudes in stores. These examples are not intended to suggest that all non-Aboriginal residents of the City of Edmonton hold discriminatory or racist views of Aboriginal peoples, rather these narratives of discrimination recounted by Aboriginal people highlight the barriers Aboriginal people face when accessing public space in the city.

Despite the difficulty in overcoming discriminatory practices, several participants highlighted the importance of the street family and provided examples of instances where Aboriginal Edmontonians have appropriated park spaces and community recreation facilities in order to host and participate in activities that celebrate Aboriginal identity and culture, facilitate information sharing and raise awareness of the contributions of Aboriginal people to the history and contemporary reality of life in Edmonton.

\subsection{Recommendations}


The findings summarized above all highlight the need for greater information sharing, engagement and meaningful dialogue between the Aboriginal community, Community Service Organizations, City officials, and Edmontonians in general. As the Aboriginal population in the city grows, scheduled redevelopment projects begin, and new residents arrive in Edmonton; tensions over the accessibility of public space are likely to increase. For this reason, it is important for policy makers, Community Service Organizations, the City of Edmonton and others institutions that create, manage and regulate public space to reach out to the Aboriginal community in Edmonton, work collaboratively to ensure Aboriginal people have the capacity to engage meaningfully in planning discussions, and expand planning and decision making processes to facilitate the right of participation for Aboriginal peoples.

The findings above also highlight the need to re-conceptualize the process of urban planning, to broaden the types of tools and techniques used by planners, and ensure individual and community perspectives on the representational nature of spaces are incorporated into the planning process. In order to do this, the following recommendations are put forward:

Recommendation 1: Renew and Expand the Urban Aboriginal Community Dialogue Process

The Urban Aboriginal Community Dialogue Process ${ }^{67}$ began in October of 2005 as part of the City of Edmonton's effort to develop an Urban Aboriginal Accord and

\footnotetext{
${ }^{67}$ For more information on the Edmonton Urban Aboriginal Community Dialogue Process see: http://www.edmonton.ca/city government/initiatives_innovation/edmonton-urban-aboriginal-accordinitiative.aspx
} 
provide opportunities for Aboriginal people to share their perspectives and identify priorities. The process created Community Leaders' Gatherings, an Elders Circle and Action Circles. Once the initiative was complete however, the gatherings and circles were dismantled.

These gatherings and circles should be re-created and expanded so that an Action Circle and/or Community Leaders Gathering occurs in each of the communities. These Circles and/or Gatherings should be supported and facilitated by the City of Edmonton Aboriginal Relations Office, and held in Community League buildings, as part of the regularly scheduled Community League meetings. Efforts should be made to ensure the Circles and/or Gatherings include a broad representation of the Aboriginal community, including First Nations, Inuit and Métis people, Elders, youth, and individuals of all genders.

The Circles and Gatherings will be used to provide Aboriginal people with an opportunity to plan and coordinate activities within the community, provide advice on community development plans, revitalization plans and public art/beautification projects and be more involved in the decision making process within the Community Leagues. This process will also increase interactions between the Aboriginal community, City of Edmonton officials (particularly those in the Planning Service Centre, the Edmonton Design Committee and the Parks and Recreation Department within the City) and Community League representatives, and may facilitate improved relationships. In addition, the consistent involvement of Aboriginal people is the planning, design and decision making around public space will help bridge the division between conceived and 
perceived space (as designed by planners, policy makers and regulators) and the representational or lived space as experienced by Aboriginal people.

Recommendation 2: Invest in and develop an Aboriginal Welcome Centre, as part of the Revitalization Efforts in the Downtown Core

Aboriginal people have expressed the desire for a gathering and celebration space, a place open to everyone, but designed by and for the Aboriginal community where Aboriginal people have control of the management, regulation and decision making processes.

The location of this space within the inner city communities of Downtown, McCauley, Boyle Street and Centre McDougall is important because these communities host a large population of Aboriginal people, the Centre would be close to the Greyhound Bus Depot, where most new Aboriginal people arrive, and it would located in close proximity to the large number of service providers that work with the Aboriginal Community. Additionally, the central location of the Centre would signify its importance as a civic celebration space, as it would be located in the same area as other City of Edmonton civic and celebration spaces, including Sir Winston Churchill Square, City Hall, Centennial Park, Winspear Centre, etc.

The Centre, developed in partnership with the City of Edmonton, the Alberta Tribal Chiefs, the Alberta Metis Nation, the Canadian Native Friendship Centres Association and the Aboriginal residents of Edmonton, would provide the Aboriginal community with a space to host regular community celebrations, and act as a resource center that raises awareness of Aboriginal peoples' history, their experience with 
colonialism, residential schooling and dispossession; as well as their contributions to the historic and continued sustainability and cultural vitality of the City of Edmonton. The Centre will thus contribute to long term efforts to improve the relationship and facilitate understanding amongst Aboriginal and non-Aboriginal community members, reduce the incidence of discriminatory and racist behaviour towards Aboriginal people and reduce the barriers Aboriginal people face when accessing and appropriating public space.

\section{Recommendation 3: Research and Promote the History of Aboriginal People in the}

\section{City of Edmonton}

The City of Edmonton Aboriginal Relations Office should work with Elders in the Aboriginal Community to research and develop an interactive program that accurately portrays the history of Aboriginal peoples in Edmonton. This program could include a variety of aspects including an identification of places of historical significance for the Aboriginal community in Edmonton, the development of Aboriginal history tours or visitor information, and the creation of a curriculum on Aboriginal history in Edmonton for use in the Edmonton Public School and Catholic School systems. This incorporation of Aboriginal history into the narrative of the City of Edmonton and the celebration of Aboriginal contributions to the city would highlight the historical and contemporary presence of the Aboriginal community in Edmonton, thus combatting the perception that Aboriginal people are new to the city, or are that Aboriginal culture is incompatible with urban life. This would also improve awareness and understanding of the contemporary experience of Aboriginal peoples, which may reduce the exclusionary and often discriminatory treatment of Aboriginal peoples. 


\section{Opportunities for Further Research}

Lastly, the discussion within this thesis highlights the need for research into the experiences of Aboriginal people in accessing other dimensions of city space, including housing and transit and the implications this has for social inclusion. Additionally, this examination of the right to the city for Aboriginal people raises the question of the relationship between the struggle of the Aboriginal community to assert the right to the city and the larger politics of resistance against neoliberalism initiated by the global urban poor. Are there opportunities for partnership, even though the experience of Aboriginal people is not limited to low-income Aboriginal peoples? Is there a role for a new urban politics and how would Aboriginal people fit into this? 


\section{Appendices}

\section{Appendix A : Key Documents Reviewed}

\begin{tabular}{|c|c|}
\hline Document Name & Obtained / Accessed: \\
\hline $\begin{array}{l}\text { City of Edmonton Parkland Bylaw } \\
2202\end{array}$ & http://www.edmonton.ca/bylaws_licences/C2202.pdf \\
\hline $\begin{array}{l}\text { Boyle Street Community Centre } \\
\text { Barring Policy }\end{array}$ & Hard copy received from representative \\
\hline $\begin{array}{l}\text { Final Report of the Boyle } \\
\text { Renaissance Advisory Committee II }\end{array}$ & $\begin{array}{l}\text { http://www.edmonton.ca/city government/documents/Bracc } \\
\text { Report2final.pdf }\end{array}$ \\
\hline $\begin{array}{l}\text { The City of Edmonton Recreation } \\
\text { Facility Master Plan }\end{array}$ & $\begin{array}{l}\text { http://www.edmonton.ca/city government/documents/PDF/ } \\
\text { RecFacilityMasterPlanAugust2004FullDoc.pdf }\end{array}$ \\
\hline $\begin{array}{l}10 \text { Year Arena Capital Development } \\
\text { Strategy }\end{array}$ & $\begin{array}{l}\text { http://www.edmonton.ca/city government/documents/PDF/ } \\
\text { ArenaStrategyApprovedFinalReportJul172007.pdf }\end{array}$ \\
\hline Urban Parks Management Plan & $\begin{array}{l}\text { http://www.edmonton.ca/city government/projects_redevel } \\
\text { opment/urban-parks-management-plan.aspx }\end{array}$ \\
\hline $\begin{array}{l}\text { The Ribbon of Green Concept and } \\
\text { Master Plan }\end{array}$ & $\begin{array}{l}\text { http://www.edmonton.ca/city_government/projects_redevel } \\
\text { opment/ribbon-of-green-concept.aspx }\end{array}$ \\
\hline $\begin{array}{l}\text { City of Edmonton Policy C513- } \\
\text { Policy on Public Engagement }\end{array}$ & http://www.edmonton.ca/for_residents/C513.pdf \\
\hline $\begin{array}{l}\text { City of Edmonton Public } \\
\text { Involvement Handbook }\end{array}$ & $\frac{\text { http://www.edmonton.ca/for_residents/Involving_Edmonton }}{\text { 2008.pdf }}$ \\
\hline $\begin{array}{l}\text { Edmonton City Council. } 2005 . \\
\text { Declaration: Strengthening } \\
\text { Relationships Between the City of } \\
\text { Edmonton and Urban Aboriginal } \\
\text { People. }\end{array}$ & $\begin{array}{l}\text { http://www.edmonton.ca/CityGov/CommServices/Edmonto } \\
\text { nUrbanAboriginalAccordDeclaration.pdf }\end{array}$ \\
\hline McCauley Revitalization Strategy & $\begin{array}{l}\text { http://www.edmonton.ca/city_government/documents/PDF/ } \\
\text { McCauleyRevitStrategy2010.pdf }\end{array}$ \\
\hline Quarters Area Redevelopment Plan & $\begin{array}{l}\text { http://www.edmonton.ca/city government/documents/Byla } \\
\text { w 15037 Q ARP.pdf }\end{array}$ \\
\hline $\begin{array}{l}\text { Quarters Streetscape Information } \\
\text { Session Summary Report }\end{array}$ & $\begin{array}{l}\text { http://www.edmonton.ca/city government/documents/PDF/ } \\
\text { Armature_SummaryReport.pdf }\end{array}$ \\
\hline $\begin{array}{l}105 \text { Street and } 102 \text { Avenue Park } \\
\text { Development description }\end{array}$ & $\begin{array}{l}\text { http://www.edmonton.ca/city government/projects redevel } \\
\text { opment/105-street-and-102-avenue-park.aspx }\end{array}$ \\
\hline $\begin{array}{l}\text { Edmonton Design Committee Bylaw } \\
14054\end{array}$ & $\begin{array}{l}\text { http://www.edmonton.ca/city government/documents/C140 } \\
\text { 54.pdf }\end{array}$ \\
\hline $\begin{array}{l}\text { The Way We Grow Municipal } \\
\text { Development Plan }\end{array}$ & $\begin{array}{l}\text { http://www.edmonton.ca/city government/documents/PDF/ } \\
\text { MDP Bylaw 15100.pdf }\end{array}$ \\
\hline $\begin{array}{l}\text { Report of the Task Force on Library } \\
\text { Services for Aboriginal Peoples }\end{array}$ & $\begin{array}{l}\text { http://www.epl.ca/ResourcesPDF/ReportOfTaskForceOnLS } \\
\text { APFeb2006.pdf\#sthash.MuaI24gt.dpuf }\end{array}$ \\
\hline
\end{tabular}




\section{Appendix B : Focus Group Facilitation Guide}

It is expected that each focus group session will take approximately 90 minutes to complete. The facilitator must be mindful of time, however participants may choose to arrive early or linger after in order to network.

\section{I: Introductions and ground rules:}

○ Introduce myself and thank participants for coming

- Identify purpose of the research

- Review confidentiality and privacy information. Inform participants of the use of an audio-recorder and seek consent

○ Review ground rules

O One person speaking at a time;

- Necessary to show respect for people's opinions;

○ Turn off cell phones and pagers; etc

- Ask participants if they have any questions

○ Ask participants to introduce themselves

\section{II: Sample Introduction:}

Hello everyone. Thank you for taking the time to come here today to speak with me. My name is Amenah Gulamhusein. I am a student from Carleton University in Ottawa and working to finish my Master of Arts in Public Administration.

My research focuses on the impact access to public space has on the level of social inclusion experienced by Aboriginal peoples living in the Downtown, Boyle Street and McCauley communities in Edmonton.

I am interested in hearing about your experiences living in Edmonton. Specifically, I would like to focus on your experiences accessing public spaces in the downtown, Boyle Street and McCauley neighbourhoods. It would also be helpful if you could tell me about your interactions with service organizations, city officials and other community members in the neighbourhood.

\section{Questions:}

Questions will be focused on 3 main topics

Topics include:

1. Defining public space and considering how it is created

2. Accessing public space- regulation and enforcement

3. Exploring the relationship between space and inclusion 
1. Defining public space and considering how it is created:

Possible questions include:

- When you hear the word public space, what do you think about?

- Do you have examples of places that you think of as public space? What is it about these places that makes them public?

- Can you think of examples of other types of public spaces that you would like to have in your community? Why do you think these types of places are important?

2. Accessing public space- regulation and enforcement:

Possible questions include:

- Why did you choose to live in this neighbourhood?

- What makes your neighbourhood a good place to live?

- Are there places in your neighbourhood that you like to go to or dislike going to?

- What makes these places different?

- How would you describe the public spaces in your community?

- Do you feel that the public spaces in your community are accessible? What makes them more or less accessible?

\section{Exploring the relationship between space and inclusion}

Asking directly about social inclusion would be ineffective because the concept is not well defined and clear. Thus, questions will focus on gaining information around the four dimensions of social inclusion: consumption, production, social interaction and political engagement. This will include questions such as:

- What kind of activities do you like to do on a regular basis? Where do you usually go to do these activities?

- Are there community events or celebrations, recreational activities, etc you enjoy attending? Where do these activities happen? Can you tell me more about these activities?

- Are there celebrations or events, recreational activities, etc you do not enjoy attending? Where do these activities happen? Can you tell me more about these? What makes them un-enjoyable?

- Can you tell me how you find information about community events, celebrations, job opportunities, training sessions, political activities, etc? Is it easy or difficult to find this information?

- Do you have friends or family that live in the city? Are you able to see them when you would like to? 
- Where do you hang out with your friends and family? Why do you like these places?

○ Do you participate in any political activity within your community (e.g. do you vote in elections, attend protests and rallies, sign petitions, participate in a NGO or other advocacy group, etc)?If you do, can you tell me about your experiences?

The questions in this guide are merely suggestions. There is no expectation that every question identified within the facilitation guide will be asked or that these questions are exclusive. Participants will be encouraged to take some control over the discussion, which will generate additional questions that are relevant to the discussion. The researcher's role within the discussion will be as a facilitator. While some sharing by the researcher may be necessary to establish rapport with participants, care will be taken to ensure the researcher does not lead the conversation. 


\section{Appendix C : Focus Group Participant List}

\begin{tabular}{|l|l|l|l|}
\hline Pseudonym & Age & Gender & Focus Group Session Date \\
\hline Chloie & 47 & F & February 21/2014 \\
\hline Lane & 33 & F & March 4/2014 \\
\hline Doreen & 45 & F & February 21/2014 \\
\hline Rain & 36 & F & March 4/2014 \\
\hline Frank & 52 & M & February 21/2014 \\
\hline Michael & 25 & M & February 19/2014 \\
\hline Jesse & 18 & M & February 19/2014 \\
\hline RJ & 17 & M & February 19/2014 \\
\hline Lois & 18 & F & February 19/2014 \\
\hline Amber & 21 & F & February 19/2014 \\
\hline Tyler & 42 & M & March 4/2014 \\
\hline Anne & 32 & M & March 4/2014 \\
\hline Willow & 44 & F & March 4/2014 \\
\hline Lewis & & & \\
\hline
\end{tabular}




\title{
Appendix D : Public Spaces Identified
}

\section{Public Spaces in Boyle Street}

Mother Theresa School Playground

St. Michael School Park

\author{
Alex Taylor School Park and Playground \\ Dawson Park \\ Boyle Street Park \\ Riverdale Park \\ Edmonton Chinese Seniors Centre \\ Zhi Yang Seniors Recreation Club \\ Boyle Street Community Hall \\ Quarters Project - Meeting Space \\ Boyle Street (Quasar) Bottle Depot \\ 18 Bus Shelters
}

\section{Public Spaces in McCauley}

Joe Clarke Athletic Grounds (includes Commonwealth Stadium)

Giovanni Caboto Park and Spray Park

Sacred Heart School Playground

McCauley Park (small green space)

McCauley School playground

Italian Canadian Seniors Association

McCauley Seniors Centre 
Stadium Transit Centre and LRT Station

11 Bus Stop Shelters

McCauley Community League

Bissell Centre Drop in

Women's Emergency Accommodation Centre

Hope Mission Jamieson Centre

Ukrainian Catholic Church

Family Worship Centre

\section{Public Spaces in Downtown}

Railtown Park

Scott Brothers Park

Sir Winston Churchill Square

Winspear Park

Citadel Theatre Indoor Garden

Post Office Clock Tower

Mary Burlie Park

Rosedale Park

Veterans Park

Beatrice Carmichael Park

McKay School Park

Beaver Hill Park

Grey Hound Bus Depot Parking Lot and Waiting Area 
Sage Seniors Association of Greater Edmonton

Golden Horizon Seniors Society

5 LRT Stations - Bay, Central, Churchill, Corona, Grandin

34 Bus Shelters

YMCA Downtown

Edmonton Public Library - Stanley Milner Branch

Salvation Army

Chinese United Church

Russian Orthodox Cathedral of St. Barbara

Boyle Street Community Services (Technically located in Central McDougall but its right on the boundary with Downtown and was consistently identified by participants) 


\section{Appendix E : List of Organizations Interviewed}

- Community Organizations

- Bissell Centre

- Boyle Street Community Services

○ Hope Mission

- YMCA Downtown Housing

○ Women's Emergency Accommodation Centre

- Salvation Army

○ Boyle Street Community League

○ McCauley Community League

○ Bottle Depot

○ Quarters Project

- Boyle Street Revitalization Association

- City Institutions

- City Parks and Recreations Department - Boyle Street, McCauley and Downtown

- Edmonton Public Library

- Edmonton Police Service 


\section{Appendix F Map of Area Studied}

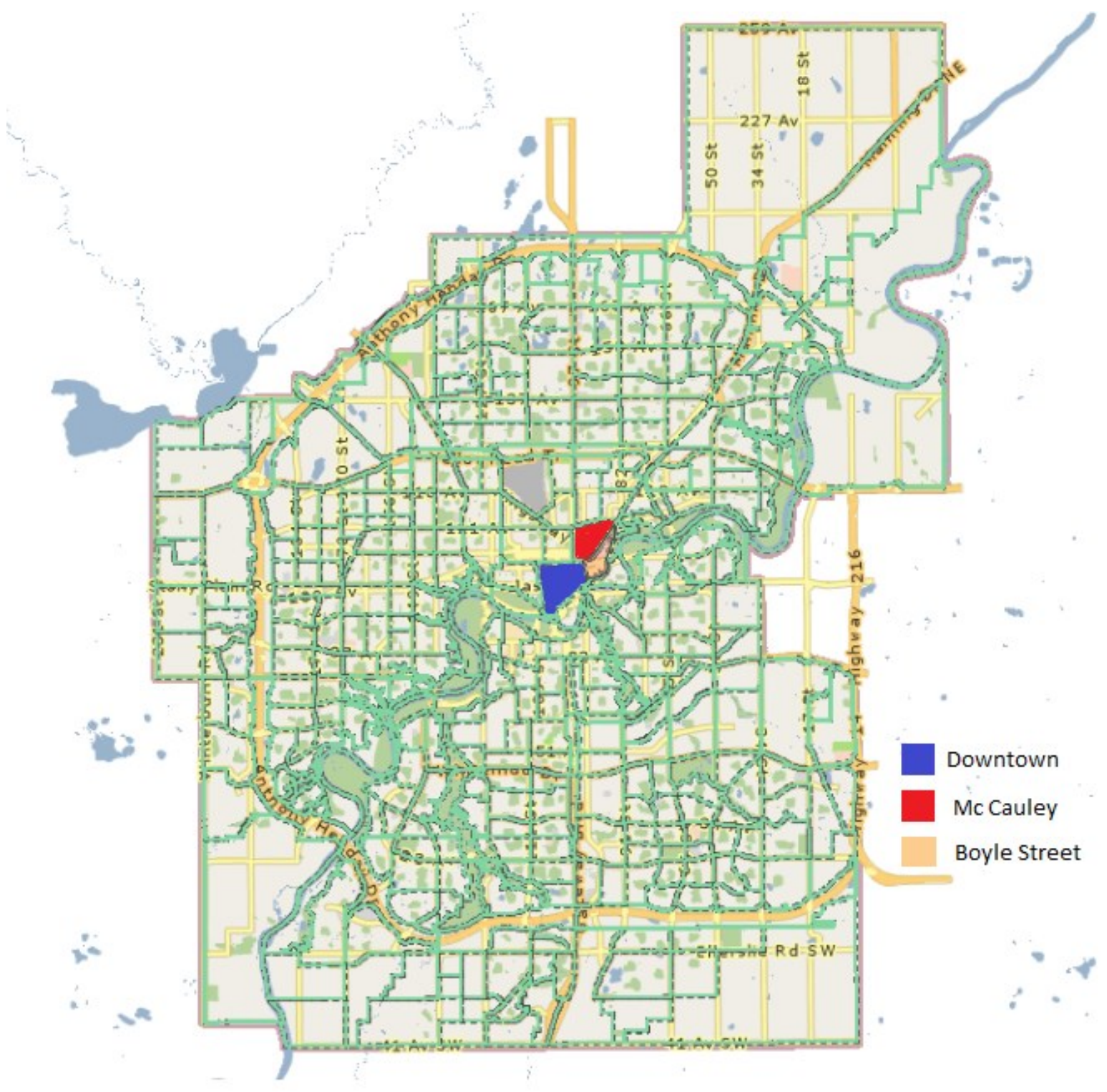

NOTE: Map Obtained from City of Edmonton Interactive Map and modified by hand to display traffic districts studied. 


\section{Bibliography}

Aboriginal Affairs and Northern Development Canada. (2010). Fact Sheet- Urban Aboriginal Population in Canada. Retrieved February 2013, from Aboriginal Affairs and Northern Development Canada: Aboriginal Affairs and Northern Development Canada

Albers, P. C., \& James, W. R. (1987). Illusion and illumination: Visual images of American Indian women in the west. In S. Armitage, \& E. Jameson (Eds.), The Women's West (pp. 35-50). Norman: University of Oklahoma Press.

Amnesty International Canada. (2004). Stolen sisters: a human rights response to discrimination and violence against Indigenous women in Canada.

Andersen, C., \& Strachan, J. (2012). Urban Aboriginal policy in a coordination vacuum: The Alberta (dis)advantage. In E. Peters (Ed.), Fields of governance 2: Making urban Aboriginal policy in Canadian municipalities (pp. 127-159). Montreal: McGill-Queen's University Press.

Anderson, K. (2000). 'The beast within': race, humanity, and animality. Environment and Planning D: Society and Space, 18, 301-320.

Anderson, K. (2007). Savagery and nature. In K. Anderson, Race and the Crisis of Humanism (pp. 35-70). Abingdon: University College London.

Atkinson, R. (2000). "Combating Social Exclusion in Europe: The New Urban Policy Challenge". Urban Studies , 37 (5-6), 1037-1055.

Avramov, D. (2002). People, Demography, and Social Exclusion. Population Studies Series , 37.

Barata, P. (2000). Social exclusion in Europe: Survey of the literature. Toronto: Laidlaw Foundation.

Barron, F. L. (1984). A summary of federal Indian policy in the Canadian west, 18671984. Native Studies Review , 1 (1), 28-39.

Bauder, H., \& Sharpe, B. (2002). Residential segregation of visible minorities in Canada's gateway cities. The Canadian Geographer, 204-222.

Beads, T., \& Kuokkanen, R. (2007). Aboriginal Feminist Action on Violence Against Women. In J. Green (Ed.), Making Space for Ingigenous Feminism (pp. 221-230). Black Point: Fernwood Publishing.

Blomley, N. (2004). Unsettling the City: Urban Land and the Politics of Property. New York: Routledge. 
Blundell, S. (1986). The origins of civilization in Greek \& Roman thought. London: Croom Helm.

Bollman, R., \& Briggs, B. (1991). Urbanization in Canada. Canadian Social Trends , 21, $22-27$.

Borrows, J. (2000). Domesticating doctrines: Aboriginal peoples after the Royal Commission. McGill Law Journal , 46, 615.

Borrows, J. (2002). Living between Water and Rocks: First Nations, Environmental Planning, and Democracy. In J. Borrows, Recovering Canada: The Resurgence of Indigenous Law (pp. 29-55). Toronto: University of Toronto Press.

Breton, E., \& Akian, G. G. (1978). Urban Institutions and People of Indian Ancestry: Suggestions for Research . Montreal: Institute for Research on Public Policy.

Buddle, K. (2011). Urban Aboriginal Gangs and Street Sociallity in the Canadian West: Places, Performances, and Predicaments of Transition. In C. Proulx, \& H. A. Howard (Eds.), Aboriginal peoples in Canadian cities: transformations and continuities (pp. 171203). Waterloo: Wilfrid Laurier University Press.

Bunge, W. (1975). Canadian alternative; survival, expedition and urban change. Toronto: Atkinson College.

Burchardt, T., Le Grand, J., \& Piachaud, D. (2002). Degrees of Exclusion: Developing a Dynamic Multidimensional Measure. In J. Hills, J. Le Grand, \& D. Pichaud (Eds.), Understanding Social Exclusion. Oxford: Oxford University Press.

Caidi, N., \& Allard, D. (2005). Social inclusion of newcomers to Canada: An information problem? Library \& Information Science Research , 27, 302-324.

Cameron, C. (2006). Geographies of welfare and exclusion: Social Inclusion and Exception. Progress in Human Geography, 30 (3), 396-404.

Cardinal, N. (2006). The exclusive city: Identifying, measuring, and drawing attention to Aboriginal and Indigenous experiences in an urban context. Cities , 23 (3), 217-228.

Chisholm, S. (2001). Housing and Social Inclusion: Asking the Right Questions. Canadian Council on Social Development. Ottawa.

City of Edmonton. (2010). Downtown Edmonton Commercial, Office and Residential Forecasts.

City of Edmonton. (2009). Urban Aboriginal Population: A Statistical Profile of Aboriginal Peoples Living in the City of Edmonton. The Aboriginal Relations Office. Edmonton: City of Edmonton. 
Cooke, M., \& Belanger, D. (2006). Migration Theories and First Nations Mobility: Towards a Systems Perspective. Canadian Review of Sociology , 43 (2), 141-164. Culhane, D. (2003). Their Spirits Live within Us: Aboriginal Women in Downtown Eastside Vancouver Emerging into Visibility. The American Indian Quarterly , 27 (3\&4), 593-606.

Davies, J. S. (2005). The Social Exclusion Debate: Strategies, Controversies and Dilemmas. Policy Studies , 26, 3-27.

Dawn, M.-H. (2003). She no speaks and other colonial constructs of "the traditional woman'. In B. Lawrence, \& K. Anderson (Eds.), Strong Women Stories: Native Vision and Community Survival (pp. 106-120). Toronto: Sumach Press.

de Haan, A., \& Maxwell, S. (1998). Poverty and social exclusion in north and south. IDS Bulletin, 29 (1), 1-9.

Dempsey, H. A. (1988). Indian Tribes in Alberta. Calgary: Glenbow Museum.

Denton, T. (1970). Strangers in Their Land: A Study of Migration from a Canadian Indian Reserve. Unpublished Doctorate Thesis .

Distaslo, J., Sylvester, G., Jaccubucci, C., Mulligan, S., \& Sargent, K. (2004). First Nations/Metis/Inuit mobility study: Final report. Institute of Urban Studies: University of Winnipeg; Assembley of Manitoba Chiefs; Manitoba Metis Federation.

Doherty, Busch-Geertsema, V., Karpuskiene, V., Korhonen, J. K., O’Sullivan, E., Sahlin, I., et al. (2008). Homelessness and Exclusion: Regulating Public Space in European Cities. Surveillance \& Society, 5 (3), 1477-7487.

Donnelly, P., \& Coakley, J. (2002). The Role of Recreation in Promoting Social Inclusion. Toronto: Laidlaw Foundation.

Dooley, M., Curtis, L., Lipman, E., \& Feeny, D. (1998). Child psychiatric disorders, poor school performance and social problems: The roles of family structure and low-income. In M. Corak (Ed.), Labour Markets, Social Institutions, and the Future of Canada's Children. Ottawa: Statistics Canada.

Du Toit, A. (2004). "Social exclusion” Discourse and Chronic Poverty: A South African Case Study. Development and Change , 35, 987-1010.

Ebersold, S. (1998). Exclusion and disability. Organization for Economic Co-operation and Development: Centre for Educational Research and Innovation.

Fixico, D. (2006). Daily Life of Native Americans in the Twentieth Century. Westport: Greenwood Publishing Group. 
Francis, D. (1992). The imaginary Indian: the image of the Indian in Canadian culture. Vancouver: Arsenal Pulp Press.

Freiler, C. (2001). From experiences of exclusion to a vision of inclusion: What needs to change? Laidlaw Foundation Conference on Social Inclusion.

Frideres, J. (1996). The royal commission on aboriginal peoples: The route to selfgovernment. Canadian Journal of Native Studies , 16 (2), 247-266.

Furniss, E. (1999). Indians, Odysseys and Vast, Empty Lands: The Myth of the Frontier in the Canadian Justice System. Anthropologica , 41 (2), 195-208.

Gerber, L. (1984). Community Characteristics and Out-Migration from Canadian Indian Reserves: Path Analysis. The Canadian Review of Sociology, 145-165.

Gilchrist, K. (2010). "Newsworthy” Victims? Feminist Media Studies, 10 (4), 373-390. Goldie, T. (1989). Fear and temptation: The image of the Indigene in Canadian, Australian, and New Zealand literatures. Montreal: McGill-Queen's University Press.

Government of Alberta. (2013). Aboriginal Peoples of Alberta: Yesterday, Today, and Tomorrow.

Graham, K. A., \& Peters, E. (2002). Aboriginal communities and urban sustainability. Ottawa: Canadian Policy Research Networks.

Groves, R. (1999). Urban Aboriginal Governance in Canada: Re-Fashioning the Dialogue. Ottawa: National Association of Friendship Centres.

Hall, S. (1995). The question of cultural identity. In S. Hall, D. Held, D. Hubert, \& K. Thompson (Eds.), Modernity: An introduction to modern societies (pp. 595-634). London: Polity.

Hanselmann, C. (2001). Urban aboriginal people in western Canada. Calgary: CanadaWest Foundation.

Hanselmann, C., \& Gibbins, R. (2003). Another Voice Is Needed:Intergovernmentalism in the Urban Aboriginal Context. In M. Murphy (Ed.), Canada: The State of the Federation 2003 Reconfiguring Aboriginal - State Relations (pp. 77-). Montreal: McGillQueen's University Press.

Harding, R. (2006). Historical representations of aboriginal people in the Canadian news media. Discourse \& Society, 17 (2), 205-235.

Harper, A. O. (2009). Sisters in Spirit. In G. G. Valaskasis, M. D. Stout, \& E. Guimond (Eds.), Restoring the Balance: First Nations Women, Community and Culture (pp. 175199). Winnipeg: University of Manitoba Press. 
Harris, R. (2002). Making native space: Colonialism, resistance and reserves in British Columbia. Vancouver: UBC Press.

Harvey, D. (2012). Rebel Cities: From the Right to the City to the Urban Revolution. London: Verso.

Harvey, D. (1999). Social movements and the city: A theoretical positioning. In O. G. (ed) (Ed.). Singapore: Urban Redevelopment Authority and the Institute of Policy Studies.

Harvey, D. (1973). SocialJustice and the City. Baltimore: Edward Arnold and The Johns Hopkins University Press.

Harvey, D. (2003). The Right to the City. InternationalJournal of Urban and Regional Research , 27 (4), 939-41.

Henry, F., \& Tator, C. (2000). The Theory and Practice of Racism in Canada. In M. Kalbach, \& W. Kalbach (Eds.), Perspectives on Ethnicity in Canada: A Reader (pp. 285302). Toronto: Harcourt Brace.

Howard-Bobiwash, H. (2003). Women's class strategies as activism in Native community building in Toronto. American Indian Quarterly, 27 (3-4), 566-582.

Jaccoud, M., \& Brassard, R. (2003). The marginalization of Aboriginal women in Montréal. In D. Newhouse, \& E. Peters (Eds.), Not strangers in these parts: Urban Aboriginal peoples (pp. 131-45). Ottawa: Policy Research Initiative.

Janovicek, N. (2003). 'Assisting our own': Urban Migration, Self-Governance, and Native Women's Organizing in Thunder Bay, Ontario, 1972-1989. American Indian Quarterly, 27 (3-4), 548-565.

Jiwani, Y., \& Young, M. (2006). Missing and murdered women: reproducing marginality in news discourse. Canadian Journal of Communication , 31, 895-917.

Johnston, G. (1987). An Intolerable Burden of Meaning : Native People in White Fiction. In T. King, C. Calver, \& H. Hoy (Eds.), The Native in Literature :Canadian and Comparative Perspectives (pp. 50-65). Toronto: ECW Press.

Kerr, D., \& Michalski, J. (2014). Family poverty in Canada: Correlates, coping strategies, and consequences. In D. Cheal (Ed.), Canadian families today: New perspectives (3 ed., pp. 185-207). Oxford: Don Mills.

Krouse, S., \& Howard, H. (Eds.). (2009). Keeping the campfires going: Native women's activism in urban communities. Omaha: University of Nebraska Press.

Lawrence, B. (2004). "Real" Indians and Others: Mixed-blood urban naive peoples and Indigenous nationhood. Vancouver: UBC Press. 
Lefebvre, H. (1991). The Production of Space. (D. Nicholson-Smith, Trans.) Oxford, England: Blackwell Publishers.

Lobo, S. (2001). Is urban a person or a place? Characteristics of urban Indian. In S. Lobo, \& K. Peters (Eds.), American Indians and the Urban Experience (pp. 73-85). New York: Altamira Press.

Loxley, J., \& Wein, F. (2003). Urban Aboriginal Development. In D. Newhouse, \& E. Peters (Eds.), Not strangers in these parts: Urban Aboriginal peoples (pp. 217-242). Ottawa: Policy Research Initiative.

Luxton, M. (2002). Feminist Perspectives on Social Iinclusion and Children's Wellbeing.

Lynch, K. (1977). The Image of the City. Massachussetts Institute of technology Press.

Madanipour, A. (1998). Social exclusion and space. In A. Madanipour (Ed.), Social exclusion in European cities: processes, experiences, and responses (pp. 75-94). London and Philadelphia: Jessica Kingsley Publishers Ltd.

Mandel, E. (1987). Imagining Natives : White Perspectives on Native Peoples. In K. Thomas, C. Calver, \& H. Hoy (Eds.), The Native in Literature : Canadian and Comparative Perspectives (pp. 34-47). Toronto: ECW Press.

Marcuse, P. (2002). Of States and Cities: The Partitioning of Urban Space. London: Oxford University Press.

McClintock, A. (1995). Imperial Leather: Race, Gender and Sexuality in the Colonial Contest. London: Routledge.

Miller, J. R. (1990). Owen Glendower, Hotspur, and Canadian Indian Policy. Ethnohistory, 386-415.

Mitchell, A., \& Shillington, R. (2002). Poverty, Inequality, and Social Inclusion. Toronto: Laidlaw Foundation.

Mitchell, D. (2003). The Right to the City: Social Justice and the Fight for Public Space. New York: The Guilford Press.

Nagler, M. (1970). Indians in the City: A Study of the Urbanization of Indians in Toronto. . Ottawa: Canadian Resource Centre for Anthropology, St. Paul University.

Native Women's Association of Canada. (2009). Voices of our Sisters in Spirit: A Research and Policy Report to Families and Communities. Ottawa: Native Women's Association of Canada. 
Norris, M. J., \& Clatworthy, S. (2003). Aboriginal mobility and migration within urban Canada: Outcomes, factors and implications. In D. Newhouse, \& E. Peters (Eds.), Not strangers in these parts: Urban Aboriginal peoples (pp. 51-78). Ottawa: Policy Research Initiative.

Norris, M. J., \& Clatworthy, S. (2011). Urbanization and Migration Patterns of Aboriginal Populations in Canada: A Half Century in Review. Aboriginal Policy Studies , $1(1), 13-77$.

Norris, M. J., Clatworthy, S., \& Peters, E. (2013). The Urbanization of Aboriginal Populations in Canada. In E. Peters, \& C. Andersen (Eds.), Indigenous in the City: Contempoary identites and cultural innovation (pp. 29-45). Vancouver: UBC Press.

Oxoby, R. (2009). Understanding social inclusion, social cohesion and socil capital. Calgary: Laurier Centre For Economic Research and Policy Analysis.

Park, R. E. (1926). The Urban Community as a Spacial Pattern and a Moral Order. In E. W. Burgess (Ed.), The Urban Community (pp. 3-18). Chicago: Chicago University Press.

Peters E. J. (2002a). "Our City Indians": Negotiating the Meaning of First Nations Urbanisation in Canada, 1945 -1975. Historical Geography, 30, 75-92.

Peters, E. J. (2002b). Aboriginal People in Urban Areas. In Urban Affairs: Back On the Policy Agenda (pp. 45-70).

Peters, E. (2005). 'Indigeneity and Marginalisation: Planning for and With Urban Aboriginal Communities in Canada . Progress in Planning , 63 (4), 327-404.

Peters, E. J. (2001). Developing Federal Policy for First Nations People in Urban Areas 1945-1975. The Canadian Journal of Native Studies , 10 (1), 57-96.

Peters, E. (1996). 'Urban' and 'Aboriginal': An impossible contradiction? In J. Claufield, \& L. Peake (Eds.), City lives and city forms: critical research and Canadian urbanism (pp. 47-62). Toronto: University of Toronto Press.

Polese, M., \& Stren, R. (2000). Social Sustainability of Cities. Diversity and the Management of Change. Toronto: $\mathrm{U}$ of T Press.

Pratt, G. (2005). Abandoned women and spaces of exception. Antipode , 37 (5), 10521078.

Proulx, C. (2011). A Critical Discourse Analysis of John Stackhouses's "Welcome to Harlem on the Prairies". In C. Proulx, \& H. A. Howard (Eds.), Aboriginal peoples in Canadian cities: transformations and continuities (pp. 143-170). Waterloo: Wilfrid Laurier University Press. 
Proulx, C. (2006). Aboriginal identification in North American cities. The Canadian Journal of Native Studies , 26 (2), 405-438.

Proulx, C. (2003). Reclaiming Aboriginal Justice, Identity and Community. Saskatoon: Purich Publishing.

Raby, S. (1973). Indian Land Surrenders in Southern Sakatchewan. The Canadian Geographer, 17 (1), 36-52.

Razack, S. (2000). Gendered racial violence and spacialized justice: the murder of Pamela George. Canadian Journal of Law and Society , 15 (2), 91-130.

Reeves, W., \& Frideres, J. (1981). Government Policy and Indian Urbanization: The Alberta Case. Canadian Public Policy, 7 (4), 584-595.

Ribot, J. C., \& Peluso, N. L. (2003). A Theory of Access. Rural Sociology, 68 (2), 153181.

Robinson, P. (2000). Employment and Social Inclusion. In P. Askonas, \& A. Stewart (Eds.), Social Inclusion: Possibilities and tensions. London: Mac Millan Press.

Royal Commission on Aboriginal Peoples. (1996). Volume 1 - Looking Forward Looking Back. Ottawa: Minister of Supply and Services.

Royal Commission on Aboriginal Peoples. (1996). Volume 4 - Perspectives and Realities. Ottawa: Minister of Supply and Services.

Sahlins, M. (1999). What is Anthropological Enlightenment? Some Lessons of the Twentieth Century. Annual Review of Anthropology, i-xxiii.

Said, E. (1994). Culture and imperialism. New York: Knopf.

Sanderson, F., \& Howard-Bobiwash, H. (1997). The meeting place : Aboriginal life in Toronto. Toronto: Native Canadian Centre of Toronto.

Shorten, L. (1991). Without Reserve: Stories from Urban Natives. Edmonton: NeWest Press.

Silver, J., Ghorayshi, P., Hay, J., \& Klyne, D. (2006). In a Voice of Their Own: Urban Aboriginal Community Development. Ottawa: Canadian Centre Policy Alternatives.

Smith, N., \& Godlewska, A. (1994). Introduction: Critical geographies of Empire. In N. Smith, \& A. Godlewska (Eds.), Geography and empire (pp. 1-8). Oxford: Blackwell.

Soja, E. (2010). Seeking spatial justice. Minneapolis: University of Minnesota Press. 
Stanbury, W. (1975). Success \& Failure: Indians in Urban Society. . Vancouver: University of British Columbia Press.

Sterritt, A. (2007). Racialization of Poverty: Indigenous Women, the Indian Act and Systemic Oppression. Vancouver: Vancouver Status of Women's Racialization of Poverty Project.

Stranger-Ross, J. (2008). Municipal Colonialism in Vancouver:City Planning and the Conflict over Indian Reserves, 1928-1950s. The Canadian Historical Review , 89 (4), 541-580.

Stren, R. (2001). Thinking About Urban Inclusiveness. University of Toronto, Centre for Urban and Community Studies. Toronto: University of Toronto.

Todd, R. (2000). Between the land and the city: Aboriginal agency, culture and governance in urban areas. London Journal of Canadian Studies , 16, 48-66.

Tomiak, J. (2013). Indigenous Governance in Winnipeg and Ottawa: Making Space for Self-Determination. In J. P. White, \& J. Bruhn (Eds.), Aboriginal Policy Research: Exploring the Urban Landscape (Vol. 8, pp. 31-54). Ottawa: Thompson Educational Publishing.

Tomiak, J. (2011). Indigenous Self-Determination, Neoliberalization, and the Right to the City: Rescaling Aboriginal Governance in Ottawa and Winnipeg. Ottawa: Carleton University.

Trujano, C. Y. (2008). Indigenous Routes: A Framework for Understanding Indigenous Migration. Geneva: International Organization for Migration.

(2007). Urban Aboriginal Task Force.

Valaskakis, G. G. (1993). Parallel Voices: Indians and Others -- Narratives of Cultural Struggle. Canadian Journal of Communicaton , 18 (3).

Weaver, H. (2009). The Colonial Context of Violence: Reflections on Violence in the Lives of Native American Women. Journal of Interpersonal Violence , 1552-1563. Weaver, S. (1981 ). Making Canadian Indian Policy: The Hidden Agenda 1968-1970. Toronto: University of Toronto Press.

Weston, M. A. (1996). Native Americans in the News: Images of Indians in the Twentieth Century Press. Westport: Greenwood Press.

Williams, A. (1997). Canadian Urban Aboriginals: A Focus on Aboriginal Women in Toronto. The Canadian Journal of Native Studies , 75-101. 
Wilson, D., \& Macdonald, D. (2010). The Income Gap Between Aboriginal Peoples and the Rest of Canada. Ottawa: Canadian Centre for Policy Alternatives.

Wilson, K., \& Peters, E. (2005). "You can make a place for it": remapping urban First Nations spaces of identity. Environment and Planning D: Society and Space , 23, 395413.

Wotherspoon, T. (2003). Prospects for a New Middle Class Among Urban Aboriginal People. In D. Newhouse, \& E. Peters (Eds.), Not Strangers in These Parts: Urban Aboriginal Peoples (pp. 147-165). Ottawa: Policy Research Initiative. 